\title{
Animal Models of Bone Metastasis
}

\author{
J. K. Simmons ${ }^{1}$, B. E. Hildreth $\mathrm{II}^{2}$, W. Supsavhad ${ }^{1}$, S. M. Elshafae ${ }^{1}$, B. B. Hassan ${ }^{1}$, W. P. \\ Dirksen ${ }^{1}$, R. E. Toribio ${ }^{2}$, and T. J. Rosol ${ }^{1}$ \\ ${ }^{1}$ Department of Veterinary Biosciences, The Ohio State University, Columbus, OH, USA \\ ${ }^{2}$ Department of Veterinary Clinical Sciences, The Ohio State University, Columbus, $\mathrm{OH}$, USA
}

\begin{abstract}
Bone is one of the most common sites of cancer metastasis in humans and is a significant source of morbidity and mortality. Bone metastases are considered incurable and result in pain, pathologic fracture, and decreased quality of life. Animal models of skeletal metastases are essential to improve the understanding of the molecular pathways of cancer metastasis and growth in bone and to develop new therapies to inhibit and prevent bone metastases. The ideal animal model should be clinically relevant, reproducible, and representative of human disease. Currently, an ideal model does not exist; however, understanding the strengths and weaknesses of the available models will lead to proper study design and successful cancer research. This review provides an overview of the current in vivo animal models used in the study of skeletal metastases or local tumor invasion into bone and focuses on mammary and prostate cancer, lymphoma, multiple myeloma, head and neck squamous cell carcinoma, and miscellaneous tumors that metastasize to bone.
\end{abstract}

\section{Keywords}

cancer; mammary; prostate; squamous cell carcinoma; dog; cat; parathyroid hormone; related protein; osteoblastic

Cancer is the second leading cause of death in the United States, behind only heart disease. Death in patients with cancer is often due to metastasis, and one of the most common sites is bone. ${ }^{109}$ Skeletal metastases are frequent in patients with breast, prostate, and lung cancer but also occur in other tumors such as myeloma, thyroid and renal cancer, lymphoma, Ewing sarcoma, and infrequently in other cancers. ${ }^{110,146}$ Bone metastases can result in osteolytic (bone-resorbing) or osteoblastic (bone-forming) metastases that can cause pain, pathologic fractures, and mortality. ${ }^{108,163}$

The general pathogenesis of bone metastasis involves proliferation of the primary neoplasm, local tissue invasion, intravasation into blood vessels, extravasation into the bone marrow, a

Reprints and permission: sagepub.com/journalsPermissions.nav

Corresponding Author: T. J. Rosol, Department of Veterinary Biosciences, The Ohio State University, 1925 Coffey Rd., Columbus, OH 43210, USA. rosol.1 @ osu.edu.

Declaration of Conflicting Interests

The author(s) declared no potential conflicts of interest with respect to the research, authorship, and/or publication of this article. 
variable time of tumor cell dormancy, proliferation in bone, and modification of the bone microenvironment. ${ }^{30}$ The current hypothesis for preferential localization of cancer cells in bone is the "seed and soil" hypothesis of Paget, ${ }^{95}$ which states that neoplastic cells (seeds) grow or proliferate only in a suitable soil, such as the bone marrow. This hypothesis has remained intact for over 100 years; however, now there is a deeper appreciation for the important role that the bone marrow microenvironment plays in metastasis. The metastatic tumor cells and the bone marrow microenvironment likely modify each other to create a milieu that is suitable for metastasis growth with the production and release of proliferationand survival-promoting cytokines. It is recognized that neoplastic cells that localize to the bone marrow may remain dormant for a variable period of time (months to years) or never cause an overt metastasis. ${ }^{163}$ The activation of proliferation in dormant metastatic cells or micrometastases within the bone marrow is an important gap in the current understanding of pathogenesis of bone metastasis.

To prevent metastasis to bone or growth of bone metastases, the molecular pathways involved in cancer metastasis must be understood. ${ }^{106,115}$ Animal models of metastasis are necessary to characterize and investigate these pathways. The ideal animal model should be clinically relevant, recapitulate the human disease, and be reproducible. There are numerous approaches to developing animal models of metastasis, including clinical trials in companion animals with spontaneous cancers, chemically or genetically induced cancer models, and xenograft models of human and animal cancers. Each model has advantages and disadvantages, and no single ideal model yet exists. Scientists must select the most appropriate model available to address the specific question or hypothesis. Important considerations for this choice include the host species, source of neoplastic cells, metastatic pathway, and clinical applicability of the model. This review describes in vivo animal models available for bone metastasis research.

\section{Animal Species Used for Bone Metastasis Research}

Species that are commonly used in bone metastasis research include mice, rats, dogs, and, less commonly, cats. The selection of species is often dependent on the cancer type that is being investigated, animal availability, and desired end points. Rodents are commonly used for bone metastasis investigations, and mice are more widely used compared with rats. ${ }^{124}$ Rodents are easy to handle, are relatively inexpensive, can be genetically manipulated, and have a relatively high degree of genetic and organ homology with humans. ${ }^{20}$ Importantly, unlike dogs and cats, several genetically immunodeficient rodent strains are available for use in xenograft studies. A disadvantage to using immunodeficient animal models of cancer metastasis is that the role of the intact immune system cannot be investigated. ${ }^{20}$

Large animal species that contribute to metastasis research include dogs and cats. Clinical trials and collection of tumor tissues for investigation (such as occurs in tissue banks) can be used to study metastasis in spontaneous cancers in dogs and cats without adversely affecting the clinical standard of veterinary therapy. ${ }^{56,96}$ Chemically immunosuppressed laboratory dogs have become established as orthotopic cancer models, particularly in prostate cancer research. ${ }^{3,55}$ While the availability and cost often preclude the use of chemically immunosuppressed dogs in cancer research, their use as orthotopic models of bone 
metastasis can be valuable compared with rodents, particularly for translational in vivo imaging and treatment studies. Cats have a unique form of spontaneous bone metastasis in which pulmonary adenocarcinomas may metastasize to the bones of the digits. ${ }^{63}$ The use of dogs and cats as models of bone metastasis will be discussed further with regard to specific tumor types.

\section{In Vivo Injection Techniques Used to Induce Bone Metastasis}

Spontaneous bone metastases are uncommon in rodents, dogs, and cats for most tumor types, including mammary cancer. Bone metastases do occur in dogs with prostate cancer and sporadically with other cancers. ${ }^{66,109}$ Therefore, most rodent animal models of bone metastasis require in vivo injection of neoplastic cells. Common injection techniques to study bone metastasis are tail vein, intracardiac (left cardiac ventricle), intraosseous (tibia or femur), or orthotopic injections (such as the mammary or prostate glands) (Fig. 1). ${ }^{164}$ Each injection technique has advantages and disadvantages that must be considered depending on the particular study and hypothesis to be tested. ${ }^{164}$

Orthotopic injection, such as mammary fat pad for breast cancer and prostate for prostate cancer, has the potential to offer a more comprehensive model of the metastatic process, from primary tumor growth through metastasis and proliferation at a distant site. ${ }^{65}$ Depending on the tumor type, orthotopic injection can vary in its technical difficulty. Metastasis after orthotopic injection is cell line dependent, with metastasis to bone occurring much less frequently compared with soft tissue sites.

Left ventricular intracardiac injection is a common technique to investigate tumor cell circulation, vascular extravasation, and distant metastasis. This makes it a valuable technique for bone metastasis research; however, it can be a challenging technique to master. The percentage of mice that develop metastases, as well as the location and number of metastases, can be variable and depend on cell lines. Regardless, it is a standard and timehonored technique to investigate bone metastasis in vivo. Use of bioluminescent imaging immediately after intracardiac injection is helpful to confirm a successful injection, since cancer cells will circulate in all regions of the body (Figs. 2-5).

Direct injection into bone (such as the femur or tibia) is a reproducible and predictable method to investigate bone metastasis - namely, the interaction of cancer cells with bone and the bone microenvironment. ${ }^{122,135}$ It is a relatively simple technique and often causes limited morbidity to the animal. Also, neonatal mouse vertebrae (vossicles) or fragments of fetal human bone can be implanted subcutaneously in mice and used as a substrate for cancer cells. ${ }^{69}$ An advantage to the use of vossicles is that bones from genetically modified mouse strains can be used and implanted into immunodeficient mice. An advantage to the use of fetal human bone in athymic or SCID mice is that the interactions of human cancer cells with human bone can be investigated in vivo. The disadvantage of intraosseous injection of cancer cells or tissue is that it can only be used to study the final step of the metastatic cascade. While it is technically not a model of metastasis, it does allow for targeted investigation of the interactions between the tumor and bone. 
Tail vein injections are relatively simple but infrequently result in metastases to bone. After tail vein injection, the first capillary bed the cancer cells contact is the pulmonary vasculature. Tail vein injections are better suited to study pulmonary metastasis and are not often useful in skeletal metastasis research compared with other methods. ${ }^{28}$

\section{Imaging Modalities for Bone Metastases}

Perhaps as important as the animal models themselves are the imaging modalities used to monitor the location and number of metastases and their growth in vivo. Several imaging options are available. The most commonly used are bioluminescent and fluorescent imaging, high-resolution radiography, and micro-computed tomography, but positron emission tomography and single-photon emission tomography can also be used. Micro-MRI (magnetic resonance imaging) is less frequently used. The usefulness of each modality is defined by its resolution, speed of imaging or throughput, capability for in vivo or ex vivo imaging, and cost.

\section{Bioluminescent Imaging}

Bioluminescence has been used in cancer research for over 20 years and has greatly facilitated in vivo bone metastasis research since it can rapidly identify sites of metastasis in the live animal (Figs. 2-5). ${ }^{75,86,120,122,164}$ Cell lines are typically transfected or transduced with an expression vector that contains luciferase or other light-producing enzymes. Lentivirus vectors are commonly used to transduce cancer cells. Bioluminescent imaging (BLI) requires cellular adenosine triphosphate (ATP) to produce light and only detects viable tumor cells, making it useful to monitor longitudinal growth of neoplastic cells. Tumors are imaged in vivo after injection of luciferin (substrate for luciferase) using a cryogenically cooled, intensified charge-coupled device (CCD camera). ${ }^{53}$ Spatial resolution is poor, but sensitivity and signal-to-noise ratio are excellent. The sensitivity depends on the cellular expression of luciferase, and microtumors (less than a few hundred cells) can be imaged with highly expressing cells. Image processing and throughput are rapid, and instruments can image up to 5 mice at a time. Imaging time is usually a few to 60 seconds, so large numbers of animals can be rapidly processed, especially if gas anesthesia is used. BLI is relatively inexpensive, but it does require live animals and viable cells. BLI can also be performed on ex vivo tissues if conducted shortly after euthanasia.

\section{Fluorescent Imaging}

Fluorescent imaging serves a similar purpose as BLI; however, it has better spatial resolution but a lower signal-to-noise ratio due to background fluorescence. Background fluorescence can occur from many tissues, including bone, feed material on the skin or gastrointestinal tract, bedding on the skin, and urine/feces on the hair or skin. Near-infrared dyes are best because red light penetrates tissues and bone more readily than green and yellow light and has less background fluorescence. Fluorescence also requires a light source and filter sets to separate the excitation and emission wavelengths of light, which are not needed for BLI. 


\section{High-Resolution Radiography}

High-resolution radiography is useful for skeletal imaging of osteolytic metastases in small animals (eg, Faxitron Optics, Tucson, AZ). It is relatively inexpensive, is rapid, and can be done in vivo or ex vivo. The resolution is up to 80 line pairs (1p)/mm (Figs. 6, 7).

Radiography is insensitive for identification of small bone metastases and metastases that do not induce significant bone lysis; therefore, enumerating bone metastases is best accomplished with BLI. It can be difficult to evaluate intramedullary bone formation, but periosteal bone proliferation can be more easily visualized with radiography.

\section{Micro-Computed Tomography}

Micro-computed tomography $(\mu \mathrm{CT})$ is an imaging modality that allows for the acquisition and analysis of the 3-dimensional structure of bone both in vivo or ex vivo at micrometer resolution. ${ }^{85}$ Its ability to provide high spatial resolution of bone metastases makes it an excellent tool for investigations, particularly in rodents (Figs. 8, 9). Resolution in living animals ranges from 50 to 100 microns, but resolutions of $\_20$ microns can be achieved ex vivo. ${ }^{59} \mu \mathrm{CT}$ can provide both qualitative as well as quantitative data and can analyze bone mineral density, trabecular number and thickness, and bone surface area. By means of finite element analysis, $\mu \mathrm{CT}$ data can be used to assess the biomechanical properties of bone, including the influence of bone metastases. A downside is that the cost of $\mu \mathrm{CT}$ is high for the equipment, usage fees, software, and technician time. Training is required to use the acquisition and analysis software, and sample throughput is slow compared with BLI.

\section{Micro-Positron Emission Tomography and Micro-Single-Photon Emission Tomography}

Both micro-positron emission tomography ( $\mu \mathrm{PET}$ ) and micro-single-photon emission tomography ( $\mu$ SPECT) are nuclear imaging techniques that provide a 3-dimensional image of the distribution of a radiopharmaceutical. ${ }^{51}$ These modalities have a resolution range between radiography and BLI and allow for molecular imaging in vivo by radiolabeling of molecular markers. The most common marker used in PET is ${ }^{18} \mathrm{~F}$-fluorodeoxyglucose (FDG) to detect metabolically active tumors. ${ }^{59}$ Recently, novel radiopharmaceuticals, such as very late antigen-4- and $\alpha \beta 3$ integrin-targeted radiotracers, have been developed to image intramedullary or osteoclastic bone metastases more selectively and sensitively. ${ }^{128,181}$ SPECT is more widely available and less expensive than PET, and the radiotracers tend to have a longer half-life (up to 6 hours) than PET tracers (approximately 75 seconds), making the use of PET sometimes limited. ${ }^{59}$

\section{Animal Models \\ Mammary Cancer}

Bone is one of the most common sites of breast cancer metastasis in women. The metastases are typically osteolytic and cause significant morbidity and mortality. Approximately $80 \%$ of patients with breast cancer who die have bone metastases, emphasizing their importance in the progression of the disease. ${ }^{163}$ The bone microenvironment provides a variety of 
growth factors for cancer cells, which are either secreted by the microenvironment cells or released from bone as a consequence of osteoclastic bone resorption. ${ }^{176}$ In addition, cell-tocell interactions likely contribute to dynamic and structural changes leading to bone loss and formation at the metastatic site. The average survival of patients with breast cancer following diagnosis of bone metastases is 24 to 36 months. ${ }^{94}$ The use of animal models has advanced the treatment options available for breast cancer bone metastasis. ${ }^{163}$

Spontaneous disease-Rats, mice, dogs, and cats frequently develop benign and malignant mammary neoplasms with the incidence dependent on the strain or breed. Unfortunately, spontaneous mammary cancer in these species is not typically suitable for investigations on bone metastasis. Most spontaneous mammary carcinomas in mice and rats do not metastasize and have only mild local tissue invasion. ${ }^{119}$ In addition, most mammary adenocarcinomas in rodents quickly lose their estrogen responsiveness and, therefore, are not appropriate models of estrogen-responsive breast cancer in women. Spontaneous mammary tumors in mice, depending on the strain, are typically due to the mouse mammary tumor retrovirus (MMTV), but the role of retroviruses in human mammary carcinoma is uncertain. Similarly, dogs and cats have uncommon bone metastases associated with mammary cancer. ${ }^{145}$

Chemically induced mammary neoplasia-Mammary tumors can be induced in rats by administering dimethylbenzanthracene, $\mathrm{N}$-methyl-N-nitrosourea (MNU), or N-ethyl-Nnitrosourea (ENU).$^{50}$ Mammary adenocarcinomas induced by ENU in Sprague-Dawley rats can develop pulmonary metastases and hypercalcemia, but bone metastasis does not occur in this model without passaging the tumors in rats (described below). ${ }^{129,130}$

Transgenic mouse models of mammary cancer-Transgenic models of cancer have many advantages, including their predictability and autochthonous development in an immunocompetent host. Many transgenic mouse models of mammary cancer are considered to have phenotypic and morphologic similarities to human breast cancer. ${ }^{13}$ Oncogene expression can be targeted to the mammary gland using tissue-selective promoters, such as the whey acidic protein, C3(1), and MMTV promoters. Although some transgenic models of mammary cancer will spontaneously metastasize to the lungs (such as the PyMT model), a disadvantage of transgenic models of mammary cancer is the very low incidence of bone metastases often due to rapid progression of the primary tumors.

\section{Human-derived breast cancer cell lines}

MDA-MD-231: The MDA-MD-231 cells are a time-honored cell line used for bone metastasis research. The cell line and its bone-metastasizing subclones are used in studies with intracardiac, orthotopic, intraosseous and tail vein injections. Metastases are almost exclusively to bone, and they induce osteolytic lesions 3 to 4 weeks after injection. ${ }^{165,176}$ Bisphosphonates have been shown to suppress the development of new bone metastases and progression of established bone metastases. ${ }^{94,165,176}$

MDA-MB-435: The MDA-MB-435 cell line has been injected orthotopically and into the left ventricle of the heart, which resulted in osteolytic bone metastases 3 to 5 weeks after 
implantation of the neoplastic cells. ${ }^{21,47}$ However, the origin of the cells is uncertain, and it has been suggested that they were derived from a melanoma rather than breast cancer. ${ }^{62}$

MCF-7: The human MCF-7 cells are estrogen receptor-positive cells that will form mixed osteolytic/osteoblastic bone metastases after intraosseous injection. Metastases tend to form slowly (up to 6 months) after intracardiac injection..$^{93}$

MCF-7/Neu: The MCF-7/Neu human cell line is unique because it develops osteosclerotic bone metastases 10 to 12 weeks after intracardiac injection into nude mice. ${ }^{174}$ While osteosclerotic (osteoblastic) metastases in mammary cancer are less common than osteolytic metastases, the MCR-7/Neu cells are a useful xenograft model for this less common form of the disease.

Zr-75-1: Aside from MCF-7/Neu cells, the ZR-75-1 cell line has also been used to model osteoblastic breast cancer bone metastasis after intracardiac injection in nude mice. This cell line has been used to demonstrate the important role of endothelin- 1 in the pathogenesis of osteoblastic metastases. ${ }^{175}$

\section{Murine mammary cancer cell lines}

Met-1: The Met-1 cell line was originally isolated from a primary mammary tumor in MMTV-PyMT/FVB/N mice. When Met-1 cells were injected into the left ventricle of the heart in $\mathrm{FVB} / \mathrm{NCr}$ mice, approximately $25 \%$ of the mice developed bone metastases in addition to metastases to the adrenal glands and ovaries. The Met- 1 cells formed osteolytic bone lesions when injected directly into the tibias (Figs. 10-12). ${ }^{164}$

4T1: The 4T1 cell line was derived from a spontaneous mammary gland carcinoma from a Balb/cfC3H mouse. ${ }^{176}$ The $4 \mathrm{~T} 1$ cells form tumors 7 to 10 days after orthotopic inoculation into the mammary fat pad of female Balb/c mice and subsequently develop bone and visceral organ metastases 3 to 4 weeks after inoculation. The tumor cells grow rapidly, and the visceral metastases may cause severe morbidity before the bone metastases are prominent. The advantages of orthotopic injection of the 4T1 cells are that bone metastases occur in up to $100 \%$ of the mice, whereas the intracardiac injection model is less reliable. The 4T1.2 subclone of the $4 \mathrm{~T} 1$ cell line has an increased incidence of metastasis to bone after orthotopic or intracardiac injection. ${ }^{65}$

\section{Rat mammary cancer models}

ENU1564: ENU-induced mammary tumors do not typically form bone metastases in rats. An exception to this is the ENU1564 tumor line. When injected into the left ventricle of the heart of Berlin-Druckrey IV rats, osteolytic metastases developed in the femur, spine, and skull. $^{39}$

Mammary rat metastasis tumor-1 (MRMT-1): The MRMT-1 cell line was derived from a rat mammary carcinoma. When injected intraosseously into Sprague-Dawley rats, osteolytic or mixed osteolytic/osteoblastic metastases developed. ${ }^{25,79}$ 


\section{Prostate Cancer}

It is estimated that prostate cancer resulted in $10 \%$ of all cancer deaths in American men in 2013. ${ }^{121}$ Approximately $70 \%$ to $100 \%$ of patients who die due to prostate cancer have bone metastases. ${ }^{17,80}$ Men with prostate cancer bone metastases have a $25 \%$ five-year survival rate and median survival of 40 months. ${ }^{132}$ The most common sites of bone metastases in prostate cancer are the pelvic and long bones, vertebral column, and ribs. ${ }^{44,163}$ Bone metastases in prostate cancer are unique because they are primarily osteoblastic or boneforming lesions. Several models of prostate cancer bone metastasis available use mice, rats, and dogs. Dogs in particular have proven to be valuable for both cell line development as well as allograft research. The dog is the only species other than man to spontaneously develop benign prostatic hyperplasia, prostate cancer, and subsequent osteoblastic bone metastases at a significant incidence, making it particularly valuable as a research model. ${ }^{66}$ Most dogs with prostate cancer have androgen-independent disease, so they are a model for late-stage prostate cancer in men. Animal models of prostate cancer have recently been extensively reviewed, and prostate cancer bone metastasis research will be highlighted in this review. ${ }^{123}$

Canine cell lines-Four canine prostate cancer cell lines have been used to investigate bone metastasis: DPC-1, Ace-1, Leo, and Probasco cells.

DCP-1: The DPC-1 cells originated from an 11-year-old Doberman Pinscher. ${ }^{4}$ They have been used for subcutaneous xenografts in mice and an orthotopic allograft model in immunosuppressed dogs. The subcutaneous xenografts did not develop metastases; however, the canine orthotopic model did result in mixed osteoblastic/osteolytic metastases in the pelvic bones in 2 of 12 dogs. ${ }^{3}$

Ace-1: The Ace-1 cell line was derived from an 8-year-old male castrated Labrador Retriever. The cells form mixed osteoblastic/osteolytic metastases after intratibial, intracardiac, and intravossicle injection in nude mice or rats. ${ }^{40,41,67-69,167}$ The Ace-1 cells have been particularly useful for bone metastasis research because bone metastases predominate after intracardiac injection. ${ }^{40,41,141,142}$ The Wnt pathway was shown to be important for bone formation in Ace-1 bone metastases since DKK1 (a Wnt inhibitor) completely inhibited the bone-forming phenotype of the Ace- 1 cells. ${ }^{141}$ The Ace- 1 cells have been used to develop an orthotopic model of prostate cancer in dogs with mild immunosuppression with cyclosporine A (Fig. 13) ${ }^{55}$ The dogs develop prostate tumors that can be used for molecular imaging and focal therapy research. ${ }^{116}$ Metastases have also occurred in lymph nodes and the lungs.

Leo: The Leo cell line originated from a 5-year-old mixed-breed dog and forms osteolytic bone tumors following intratibial injections into nude mice. ${ }^{143}$ Interestingly, the most common sites of metastasis for this cell line after intracardiac injection are the brain and spinal cord, which make the Leo cells a unique model for brain metastasis research.

Probasco: The most recently characterized canine prostate cancer cell line is Probasco. The Probasco cells originated from a 10.5-year-old mixed-breed dog and form dramatic 
osteoblastic bone metastases after intracardiac and intratibial injection in nude mice, making it a valuable model for studying the molecular pathways vital in bone-forming lesions (Figs. $6-9) .{ }^{122}$

\section{Human cell lines}

PC3: One of the most commonly used human prostate cancer cell lines is PC3, which was derived from a bone metastasis. ${ }^{64}$ This cell line is androgen insensitive and has been used in orthotopic, intratibial, and intracardiac injections as well as tail vein injections to demonstrate the homing ability to subcutaneously implanted human fetal and adult bone. ${ }^{170}$ The PC3 and PC3 M cells produce osteolytic tumors and metastasize to the mandible, rib, pelvis, femur, and tibia after orthotopic or intracardiac injection. ${ }^{91,177}$

Osteoblastic human cell lines: Few human prostate cancer lines develop osteoblastic skeletal metastases, but the human LAPC-9, MDA PCa $2 \mathrm{~b}$, and $\mathrm{LuCaP} 23.1$ produce the most bone-forming tumors after intraosseous injection. ${ }^{19,64,169} \mathrm{LuCaP} 23.1$ is a tumor line, in contrast to the LAPC-9 and MDA PCa $2 b$ cell lines, which is a disadvantage since the cells do not grow in vitro.

Transgenic mouse models: Most mouse models of prostate cancer do not develop metastases or progress past the invasive stage of carcinoma. ${ }^{54}$ Only the TRAMP X FBV mice are reported to uncommonly develop bone metastases with a minimal osteolytic/ osteoblastic response to the neoplastic cells. ${ }^{35,37,45,112}$

Mouse prostate reconstitution model: The basis of this model is to combine prostate cells (neoplastic or nonneoplastic) with urogenital sinus mesenchyme (either rat or mouse origin) and implant the cell mixture beneath the renal capsule of an immunodeficient mouse. ${ }^{150}$ The combination of mouse prostate tissue overexpressing both ras and myc coimplanted with mouse urogenital sinus lacking p53 was reported to develop frequent micrometastases to bone. ${ }^{140}$ While this model system provides a fascinating approach to explore the genetic pathogenesis of prostate cancer, the technical complexity often limits its utilization in prostate cancer research.

Rat prostate cancer models: Bone metastasis in rat models of prostate cancer is rare, and most prostate cancer bone metastasis research performed in rats is limited to the MATLyLu subline and the PA-III cell line. The MATLyLu subline was developed from a 22-month-old inbred Copenhagen rat and can produce osteolytic or osteoblastic (variant R3327) bone metastases after tail vein, intracardiac, or intraosseous injection. ${ }^{10,34,42,70,139}$ The PA-III cell line was derived from a Lobund-Wistar rat and has been used to produce mixed osteolytic/ osteoblastic lesions when implanted over the calvaria or scapula after disrupting the periosteum. ${ }^{11,60}$

\section{Lung Cancer}

Lung cancer is currently divided into the histologic classifications of either small cell lung cancer (SCLC) or non-small cell lung cancer (NSCLC), which differ in their biological behavior, clinical course, and response to therapy. Bone metastasis occurs in $30 \%$ to $40 \%$ of 
patients with lung cancer. ${ }^{18}$ Lung cancer metastases to bone produce predominantly osteolytic (SCLC) or mixed osteolytic/osteoblastic (NSCLC) lesions. ${ }^{29,84}$

Mouse models of bone metastasis or the local response of bone following intraosseous injection have been studied using several lung cancer cell lines, including, but not limited to, the SBC-5, SBC-3, SPC-A-1, A549, H460, H727, NCI-H292, PC-9, PC-14, ACC-LC319, LLC, H2030, and HARA cell lines. ${ }^{135}$ While tail vein, intracardiac, intraosseous, and orthotopic routes of administration have been investigated, orthotopic implantation better recapitulates the metastatic behavior of lung cancers compared with other injection routes. Intraosseous injections have included both intratibial and intraspinal locations. ${ }^{137}$ Spinal metastases of lung cancer were formed by implanting small pieces of PC-14 tumors directly into the vertebral bodies of mice. ${ }^{137}$ The tumor xenografts produced osteolysis and spinal compression consistent with spinal metastasis in human patients.

Several cell lines have undergone in vivo selection to create sublines that are more likely to metastasize to bone or metastasize exclusively to bone. Mice injected with the parent PC14 cell line developed few metastases. However, after multiple in vivo selections, the highly metastatic PC14HM subline was created, which forms bone metastases in 100\% of injected mice. ${ }^{89}$ Eight cycles of in vivo selection were also performed for the SPC-A-1 cell line following intracardiac injection to create the SPC-A-1BM cell line, which has a $100 \%$ rate of metastasis to the skeleton following intracardiac injection. ${ }^{171}$ In vivo selection of subpopulations with a high efficiency of metastasis to bone was also performed with the H460 cell line to create the H460SM subline that spontaneously metastasizes to bone, kidney, brain, soft tissue, and contralateral lung following orthotopic injection. ${ }^{38,71}$

The SCLC cell line, SBC-5, consistently formed skeletal metastases ${ }^{84}$ Intravenous administration of the SBC-5 cell line in natural killer (NK) cell-depleted SCID mice resulted in a $100 \%$ incidence of bone metastasis. ${ }^{83}$ Osteolytic bone metastases were present within the appendicular and axial skeleton and pelvis, and metastases to other organs included the lung, liver, and kidney, which resembled the human condition.

In a model investigating the role of inflammation in cancer metastasis, it was found that targeting circulating monocytes, tissue macrophages, and osteoclasts in bone through the administration of clodronate liposomes reduced both bone and muscle metastasis of HARAB cells following intracardiac administration. ${ }^{46}$ Interestingly, treatment with reveromycin A, an antibiotic that specifically targets osteoclasts, resulted in a reduction of bone but not soft tissue metastasis. ${ }^{46}$ Overexpression of the bone morphogenetic protein-2 inhibitor, noggin, and administration of the osteoclast inhibitor, RANK-Fc, inhibited both the osteoblastic and osteolytic components of bone metastases due to the NSCLC A549 cells. ${ }^{29}$

The modeling of bone metastasis in mice by subcutaneously implanting human bone in NOD/SCID mice has also received attention in lung cancer metastasis. This model allows for the interaction of human lung cancer cell lines with human bone. When the NSCLC A549 cell line was injected adjacent to a subcutaneously implanted human bone fragment, lung cancer cells invaded into the bone. ${ }^{105}$ 
The balance of sex steroids is important in osteolytic bone metastasis of lung cancer. The number of SBC- 5 bone metastases was greater in female mice compared with male mice, and there was an increase in osteoclasts in the bone metastases of both female mice and male mice undergoing androgen suppression. ${ }^{114}$

\section{Renal Cell Carcinoma}

Renal cell carcinoma (RCC) metastasizes to bone, lymph nodes, liver, lung, and the brain. ${ }^{179}$ Currently, the 5-year survival of patients with RCC and metastasis is less than $10 \% .^{92}$ The skeleton is the second most common site of metastasis following the lung and occurs in about one-third of patients. ${ }^{179} \mathrm{RCC}$ is the fourth most common cancer to metastasize to bone in people following lung, breast, and prostate cancer. Bone metastases from RCC are typically osteolytic and have a high degree of vascularity. ${ }^{27,131}$ Routes of administration of RCC cell lines include tail vein, intracardiac, and intratibial injections with human 786-O/luc, RBM1, or ACHN cell lines.

786-O/luc-The 786-O/luc cell line has reproducible osteolytic metastases to the appendicular and axial skeleton and pelvis following intracardiac administration. ${ }^{131}$

RBM1-The RBM1 cell line was developed from a humeral bone metastasis and produces osteolytic lesions following intratibial injection. ${ }^{162}$ After serial in vivo selection in a mouse intratibial injection model, a more aggressive subline, RBM1-IT4, was established. Intravenous and intracardiac administration did not result in lung or skeletal metastases.

AHCN - Parental AHCN cells develop metastases in the lung, bone, brain, ovary and the adrenal glands. ${ }^{159}$ The ACHN-BO subline (selected by 4 passages of in vivo bone metastases) metastasizes exclusively to bone. ${ }^{159}$ A clinically relevant orthotopic model of RCC bone metastasis employed tissue slices of primary human RCC and implanted them underneath the renal capsule of immunodeficient mice. Disseminated RCC cells were present within the bone marrow of mice as early as 1 month after implantation. The pattern of metastasis in mice correlated with the progression of clinical disease in the respective patients. In addition, intratibial injections of single cells isolated from the tissue slices resulted in $100 \%$ engraftment and bone tumors. ${ }^{151}$

\section{Transitional Cell Carcinoma (TCC)}

Transitional cell carcinoma (TCC) of the bladder metastasizes to the regional lymph nodes (90\%), liver (47\%), lung (45\%), and bone (32\%). ${ }^{158}$ Most deaths of patients with TCC result from metastasis. Bone metastases of TCC can be osteolytic, osteoblastic, or mixed osteoblastic-osteolytic lesions. ${ }^{15,36,49}$

There have been few models available to investigate bone metastases of TCC, primarily a result of the lack of tumorigenicity of established TCC cell lines. However, in vivo selection of bone metastases from cell lines in mice has developed more clinically relevant cell lines with regard to the development of bone metastasis. The most common example is the TCC cell line, TSU-Pr1. ${ }^{152}$ The TSU-Pr1-B1 and B2 sublines were established from subsequent bone metastases. ${ }^{15}$ The increase in metastatic potential to bone resulted from the increased 
epithelial characteristics of the sublines compared with the mesenchymal characteristics of the original TSU-Pr1 cells. ${ }^{14}$

Other TCC cell lines useful for orthotopic models of bone metastasis include (1) the metastatic M-NBT-II cell line derived from the rat bladder carcinoma cell line, NBT-II; (2) the human $253 \mathrm{~J}$ lung-IV orthotopic metastatic model; and (3) the human UM-UC-3 parent cell line and its derivative, UM-UC-3luc2, which develops bone metastases following intracardiac injection. ${ }^{7,24,153}$ The most common routes of administration for the development of bone metastasis are orthotopic and intracardiac injections. In addition, intratibial injections have been used to investigate the local effects of TCC in bone. ${ }^{14}$

Dogs have a high incidence of TCC, which results in death due to locally invasive disease or metastasis. ${ }^{58}$ Bone metastasis has been reported to occur occasionally in canine TCC, ${ }^{74}$ but while canine TCC cell lines are available, they have not been used to investigate the pathogenesis of bone metastasis. ${ }^{23}$

\section{Head and Neck Squamous Cell Carcinoma}

Head and neck squamous cell carcinoma (HNSCC) is the sixth most common cancer worldwide. ${ }^{111}$ Approximately 54000 Americans were diagnosed with HNSCC, and 11500 died of this aggressive cancer in 2013. ${ }^{121}$ The tongue and larynx are the most common sites of this cancer. The 5-year survival in HNSCC is approximately 50\%. ${ }^{52,57}$ HNSCC normally occurs in adults; however, the incidence of human papillomavirus (HPV)-related oropharyngeal squamous cell carcinoma in the younger population has been increasing. ${ }^{182}$

Although HNSCC metastasizes to regional lymph nodes, cancers that originate in the gingiva are associated with local bone invasion and lysis of the mandible and maxilla. ${ }^{75}$ More than half of the patients with HNSCC were diagnosed at the later stages of disease characterized by local bone invasion, bone destruction, and metastasis to local lymph nodes. ${ }^{125,147}$

Different types of bone invasion found in HNSCC include the erosive, infiltrative, and mixed patterns, which have different histological features and lengths of disease-free status. ${ }^{52}$ The infiltrative pattern has a lower rate of 3-year disease-free status compared with the erosive bone invasion pattern. High expression levels of PTHrP, RANKL, interleukin (IL)-6, and tumor necrosis factor- $a$ (TNF- $\alpha$ ) were detected in bone-invasive HNSCCs. ${ }^{52}$ The majority of bone-invasive HNSCCs are suspected to be mediated by PTHrP and RANKL, similar to cancers that metastasize to bone. ${ }^{52,76,133}$ PTHrP contributes to bone lysis by inducing RANKL expression in osteoblasts, resulting in binding of RANKL to its receptor, RANK, on osteoclasts and stimulating osteoclastogenesis. ${ }^{133}$ Osteoprotegerin (OPG), the soluble decoy receptor of RANKL, is regulated by the Wnt/ $\beta$-catenin signaling pathway and counterbalances the actions of RANKL. OPG inhibits osteoclastogenesis and promotes osteogenesis by blocking the interaction between RANKL and RANK. ${ }^{52,149}$ Imbalance of the RANKL/OPG ratio was suggested as the critical event for osteoclastogenesis in HNSCC. ${ }^{12,52}$ Transforming growth factor- $\beta$ (TGF- $\beta$ ) released during osteolysis was reported to not only increase tumor cell proliferation but also increase the production of PTHrP. ${ }^{133}$ EGFR is suspected to play a role in upregulating PTHrP in many 
bone-invasive cancers. ${ }^{31}$ However, the EGFR downstream signaling pathways that upregulate PTHrP still need to be elucidated.

Various animal models have been developed for studying the pathogenesis and genetic backgrounds of HNSCC. The development of novel therapies relies on preclinical research in animal models. However, relatively few models are appropriate for investigations on bone-invasive HNSCC.

Human and mouse cell lines for orthotopic mouse models of HNSCC-The orthotopic animal model has been important for investigating HNSCC-related bone invasion. ${ }^{75,77,78,125}$ However, the number of orthotopic models for bone-invasive HNSCC is limited. Only a few human HNSCC cell lines, including BHY, UMSCC, UMSCC11A, UMSCC11B, BICR31, BICR56, and HSC3, were found to invade bone in vivo. ${ }^{77}$ In this model, neoplastic cell lines are injected directly into tissues of the oral cavity or tongue of immunocompromised rodents. ${ }^{72,125}$ Genetically engineered mouse models are also available for investigations on the pathogenesis of HNSCC. ${ }^{72}$

SCCVII: The orthotopic model of mandibular bone invasion using the mouse OSCC cell line (SCCVII) demonstrated that PTHrP plays an important role in bone invasion.

Knockdown of PTHrP in SCCVII cells inhibited bone resorption and decreased osteoclast numbers in vivo. ${ }^{133}$ OPG decreased bone invasion and osteoclast numbers. ${ }^{52}$ Unfortunately, the xenografts grow rapidly, which limits usefulness of the model for long-term studies. ${ }^{125}$

YD-39: This relatively new bone-invasive human HNSCC cell line, originating from an oral squamous cell carcinoma with mandibular bone invasion, was inoculated over the calvarial bone of nude mice and found to develop prominent osteolytic lesions. ${ }^{48}$ The aggressive bone invasion and osteolysis in this model make it useful for studying the pathogenesis of these processes in HNSCC.

Spontaneous feline HNSCC and orthotopic mouse models-Spontaneous HNSCC in companion animals, especially cats, can serve as a useful natural model for HNSCC. HNSCC is particularly common in aged cats compared with other animal species. ${ }^{90}$ There is a high degree of biologic similarity between feline and human nonpapillomavirus-induced HNSCC. ${ }^{6,73}$ Cats typically present for veterinary care of HNSCC at the late stages of disease. The prognosis is grave for most cats, and time to death or euthanasia is short (2-6 months). ${ }^{136}$ Clinical trials in cats with spontaneous HNSCC are a potentially useful approach for translational cancer research and novel therapy development. ${ }^{73,134}$

Similar to humans, squamous cell carcinoma (SCC) is the most common oral cancer in cats. Ten percent of all tumors diagnosed in cats are oral tumors, and $75 \%$ of feline oral cancers are SCC. ${ }^{76,127,136}$ The tongue, especially the ventral tongue, and gingiva were reported as the most commonly affected sites for feline HNSCC. ${ }^{76}$ Remarkably, cats and humans are the only 2 species that commonly develop spontaneous lingual SCC. ${ }^{33,52,168}$ Similar to humans, HNSCC frequently occurs in aged cats with no apparent breed or sex predisposition. ${ }^{127}$ Since cats often share the same environment as their owners, cats are 
frequently exposed to the same risk factors as humans. ${ }^{6,8,73,103,168}$ Environmental tobacco smoke (ETS) exposure, flea collar use, canned foods, and papillomavirus infection have been implicated as being potentially involved in SCC development in cats. $., 103,126,182$ Adjacent bone invasion, lymph node metastasis, and spontaneous recurrence are frequent complications in this cancer. ${ }^{126,127}$ At the time of diagnosis, the disease is often in the late stages with extensive bone invasion. Spontaneous HNSCC in cats is a potential valuable model for translational research on novel drug, genetic, nanoparticle, and interventional therapies using clinical trials of client-owned cats in the clinical veterinary setting.

Similar to humans, high PTHrP expression has been found in feline oral SCC (OSCC) and is often associated with increased bone invasion and osteoclastogenesis in vivo and in vitro. ${ }^{75,76}$ Orthotopic xenograft models using feline-derived OSCC cell lines (SCCF1, F2, and F3) demonstrated that bone-invasive feline OSCC (SCCF2) had greater PTHrP messenger RNA (mRNA) expression compared with non-bone-invasive cell lines (SCCF1 and SCCF3). ${ }^{75}$ The feline HNSCC cell line, SCCF2, closely mimicked bone-invasive SCC when tumor cells were injected into the submucosa of the maxilla (Figs. 14, 15).${ }^{75}$ Bone resorption was associated with PTHrP expression, and the EGFR ligands, amphiregulin and TGF-a, were found to further increase PTHrP. In contrast, OPG mRNA expression was very low in the SCCF2 cells. Treatment with a bone resorption-inhibiting bisphosphonate, zoledronate, was found to reduce tumor growth, prevent bone loss, and inhibit bone invasion in mice carrying feline SCC orthotopic xenografts. ${ }^{75,77}$

\section{Multiple Myeloma}

Multiple myeloma (MM) is a malignant neoplasm of the differentiated B lymphocytenamely, the plasma cell. In mouse models and patients with MM, the malignant plasma cells comprise as much as $\sim 90 \%$ of the cells within the bone marrow and express high amounts of monoclonal $\gamma$-globulins. ${ }^{100}$ Increased osteoclastic activity early in the disease results in local osteolysis. However, later in the disease, there is also inhibition of osteoblastic bone formation by MM cells. ${ }^{138}$ This ultimately results in severe osteolytic bone lesions. MM also releases proangiogenic factors, which may facilitate the ability of these cells to continuously enter and exit the bone marrow. ${ }^{154}$ This results in MM metastasizing throughout the skeleton.

Tail vein, intracardiac, subcutaneous, and intraosseous (intratibial and intrasternal) routes of administration of MM cells have been reported in mice. Human MM subcutaneous tumors in SCID mice metastasized not only to bone but also to the lung, liver, and spleen. ${ }^{172,173}$ However, intratibial tumors metastasized only to other bones. Intracardiac injection of NOD/ SCID mice with MM cells collected from the peripheral circulation of clinical patients resulted in lytic bone disease. ${ }^{100}$ Injection directly into the mouse sternum resulted in lytic bone lesions and clonotypic cells in the distant femoral bone marrow.

\section{Mouse-derived models of MM}

5TMM: The 5 T mouse model (5TMM) is characterized by the spontaneous development of $\mathrm{MM}$ in aged C57BL/KaLwRij mice at a frequency of $0.5 \% .^{22,101,102}$ The disease can be transferred to younger mice for further investigation by either tail vein or direct marrow 
injection of MM cells. Parent 5TMM cells and their sublines produce disease mimicking

clinical MM in people. ${ }^{87,102}$

B9BMI: An additional syngeneic bone metastasis model embodying many features of MM in people is the B9/BM1 mouse model. ${ }^{43}$ Following intravenous injection, IL-6-dependent, IL-1-producing B9/BM1 cells localize to and engraft within the vertebral and femoral bone marrow in nonirradiated, euthymic mice.

\section{Human-derived models of MM}

ARH-77: The ARH-77 model was developed to better represent human MM and involves the intravenous injection of the human ARH-77 plasma cell leukemia cell line into irradiated SCID mice, which develop osteolytic bone lesions. ${ }^{2}$ Variations on this model include the injection of freshly isolated MM cells into irradiated SCID mice or the subcutaneous implantation of human bone samples. ${ }^{87,100,148}$

SCID-hu: The SCID-hu model has been employed to investigate MM, which involves the subcutaneous implantation of human fetal bone into SCID mice. Freshly isolated primary MM cells or human MM cell lines engraft into the subcutaneous implants and metastasize to other human fetal bone implants, but the MM cells do not metastasize to the bone marrow of the host mouse. ${ }^{148}$

\section{Leukemia and Lymphoma}

B-cell lymphoma frequently disseminates to multiple organs. It occasionally involves bone and produces osteolytic lesions, where it is associated with the development of hypercalcemia of malignancy. There has been extensive development of murine cell lines of leukemia and lymphoma with bone metastasis.

T-cell lymphoma in dogs may localize to the bone marrow and induce osteolytic bone resorption and hypercalcemia of malignancy. ${ }^{81,107}$

\section{Mouse-derived models of lymphoma and leukemia}

MH-98: Subcutaneous injection of the murine B-cell lymphoma cell line, MH-95, metastasizes to the lung, liver, kidney, spleen, and lymph nodes within 2 weeks of administration and forms osteolytic lesions in bone. ${ }^{82}$

MOC-25: The mouse lymphoma line, MOC-25, developed spontaneously in a female nude mouse and was established by intraperitoneal injection in nude mice. ${ }^{144}$ The MOC- 25 cells preferentially disseminate to the abdominal viscera following intraperitoneal or intravenous injection, but the cells eventually metastasize to the bone marrow.

MDAY-D2: Intravenous injection of the murine myeloid leukemia cell line, MDAY-D2, resulted in metastasis to hemolymphatic organs, including the spleen, liver, and bone marrow. ${ }^{26}$ 
$\mathrm{BCL}_{1}$ : Intravenous injection of the murine B-cell leukemia cell line, $\mathrm{BCL}_{1}$, results in hematogenous metastasis and is associated with disruption of the normal cellular architecture of the bone marrow. ${ }^{161}$

Mouse model of canine T-cell lymphoma-A xenograft model of canine T-cell lymphoma was developed in NOD/SCID mice. The mice developed multicentric lymphoma, humoral hypercalcemia of malignancy, and increased plasma PTHrP concentrations. ${ }^{88}$ In vivo metastases could be localized using bioluminescent imaging and luciferase-positive tumor cells.

Transgenic mouse models of lymphoma and leukemia-A subset (5\%) of people with human T-cell leukemia virus type 1 (HTLV-1) will eventually develop adult T-cell leukemia/lymphoma (ATL). Overexpression of the HTLV-1 viral oncogene Tax results in spontaneous lymphoma and leukemia and ultimately the development of osteolytic bone lesions. ${ }^{32}$ The increased expression of Tax resulted in an osteolytic bone phenotype.

In addition, a mouse model of Burkitt lymphoma was created by a Myc mutation. ${ }^{61}$

Mouse model of human adult T-cell lymphoma/leukemia (ATLL)—A human adult T-cell leukemia tumor line (RV-ATL) was adapted to SCID/Bg mice by intraperitoneal injection of tumor cells, which developed multicentric lymphoma, hypercalcemia, increased plasma PTHrP, and localization of tumor cells to the bone marrow. ${ }^{104}$

\section{Ewing Sarcoma}

The only primary bone tumor that has received attention in the development of animal models of bone metastasis is Ewing sarcoma. Ewing sarcoma is the second most common primary bone tumor affecting children and young adults younger than 20 years, representing $10 \%$ to $15 \%$ of all primary bone tumors. While osteosarcoma is the most common primary bone tumor, it primarily metastasizes to the lungs and less frequently to secondary bone sites. There are currently no animal models of bone metastasis for osteosarcoma. Ewing sarcoma usually arises in the femur, humerus, and pelvis and is associated with rapid tumor growth and bone destruction. ${ }^{156}$ Ewing sarcoma is a unique neoplasm since it has a predilection to metastasize to either the lungs or skeleton or, in some cases, to both organs. ${ }^{118}$ The mechanisms for metastasis have not been elucidated. Interestingly, metastases occur only in the lungs or bones in $50 \%$ and $40 \%$ of the patients, respectively. ${ }^{5}$ The 5-year survival rate in patients with lung metastases is $36 \%$ and less than $20 \%$ in those with bone metastases. ${ }^{97-99}$

Human-derived mouse models of Ewing sarcoma-In mouse xenograft models of skeletal metastasis of Ewing sarcoma, the most common routes of administration of cell lines are intravenous, subcutaneous, and intraosseous. Ewing sarcoma cell lines include (1) TC-71, derived from a humeral Ewing sarcoma recurrence, and (2) VH-64, derived from the pleural effusion of a patient with primary Ewing sarcoma of the metatarsal bone. ${ }^{155,157,166}$ Intravenous administration of the cell lines in NOD/SCID mice results in a pattern of metastasis similar to clinical patients; however, only $23 \%$ of mice developed bone metastasis. ${ }^{157}$ Intravenous injection of TC-71 cells in nude mice resulted in bone metastases 
(62\%) with fewer metastases to the lungs (24\%). ${ }^{118}$ Intraosseous (femur and tibia) injections of Ewing sarcoma in immunocompromised mice mimic bone tumors in clinical patients, and the mice develop distant bone metastasis. ${ }^{156}$ TC-71 cells were also injected directly into the ribs of nude mice, allowing for ease of visualization of primary tumor growth, and some mice had metastases to the lungs but not the skeleton. ${ }^{160}$

\section{Thyroid Cancer}

Cancers originating from follicular cells of the human thyroid gland are typically classified as either papillary or follicular. Well-differentiated papillary and follicular thyroid carcinomas are associated with a slowly developing clinical course and a favorable prognosis. ${ }^{113}$ However, a subset of patients $(10 \%-15 \%)$ develops metastases to the lung and bone. The 10-year survival rate following the detection of bone metastasis is less than 20\%. ${ }^{113,117}$ Thyroid carcinoma bone metastases typically have an osteolytic phenotype; however, it is believed that osteoblastic metastasis of thyroid carcinomas may have a better prognosis. ${ }^{1}$

Current models of thyroid carcinoma bone metastasis using orthotopic implantation of tumor cells have been limited because this method results in few metastases and is technically challenging. Therefore, intracardiac, intratibial, and subcutaneous routes of administration have been used. There are few thyroid cancer cell lines that metastasize to bone. The human anaplastic thyroid cancer cell lines (8505C, C-643, SW-1736, and THJ-16 T) and the follicular thyroid cancer cell lines (FTC-133, FTC-236, and FTC-238) were transfected with luciferase. ${ }^{180}$ The cell lines were then injected subcutaneously or intravenously, and metastasis was analyzed by bioluminescence imaging and histology. Intravenous injection of 8505C-Luc2 cells resulted first in lung metastasis, with many of these mice subsequently developing bone metastasis. Similarly, metastases to the lungs and other organs developed in all mice injected with the C-643-Luc2, THJ-16T-Luc2, FTC-133-Luc2, FTC- 236-Luc2, and FTC-238-Luc2 sublines. ${ }^{180}$ Intracardiac injection of the BCPAP papillary thyroid carcinoma cell line resulted in metastasis, including bone, in up to $90 \%$ of the mice. ${ }^{16}$ The intracardiac injection technique has been preferred for bone metastasis. Intratibial administration of the human WRO follicular thyroid carcinoma cell line resulted in mixed osteoblastic and osteolytic bone tumors in nude mice. ${ }^{178}$

\section{Conclusions}

Skeletal metastases have the potential to cause severe morbidity and mortality and are considered an incurable disease. To date, there are numerous established in vivo animal models of skeletal metastasis, varying by host animal, cancer type, and method of tumor injection. Animal models will continue to be vital to investigate the pathogenesis of bone metastasis. Further characterization of these models and development of novel animal models focusing on specific metastatic pathways are essential for better understanding the mechanisms of bone metastasis with the ultimate goal of identifying key targets for therapeutic intervention to improved treatment, quality of life, and patient survival. 


\section{Acknowledgments}

\section{Funding}

The author(s) disclosed receipt of the following financial support for the research, authorship, and/or publication of this article: This work was supported by the Ohio State University College of Veterinary Medicine Canine Research Funds.

\section{References}

1. Ahuja S, Ernst H. Osteoblastic bone metastases in medullary thyroid carcinoma. Strahlenther Onkol. 1991; 167(9):549-552. [PubMed: 1925939]

2. Alsina M, Boyce B, Devlin RD, et al. Development of an in vivo model of human multiple myeloma bone disease. Blood. 1996; 87(4):1495-1501. [PubMed: 8608240]

3. Anidjar M, Scarlata E, Cury FL, et al. Refining the orthotopic dog prostate cancer (DPC)-1 model to better bridge the gap between rodents and men. Prostate. 2012; 72(7):752-761. [PubMed: 21882212]

4. Anidjar M, Villette JM, Devauchelle P, et al. In vivo model mimicking natural history of dog prostate cancer using DPC-1, a new canine prostate carcinoma cell line. Prostate. 2001; 46(1):2-10. [PubMed: 11170126]

5. Avigad S, Yaniv I. Novel approaches for the management of patients with Ewing sarcoma. Future Oncol. 2006; 2(5):659-665. [PubMed: 17026457]

6. Ballegeer EA, Madrill NJ, Berger KL, et al. Evaluation of hypoxia in a feline model of head and neck cancer using (6)(4)Cu-ATSM positron emission tomography/computed tomography. BMC Cancer. 2013; 13:218. [PubMed: 23631652]

7. Bellusci S, Moens G, Thiery JP, et al. A scatter factor-like factor is produced by a metastatic variant of a rat bladder carcinoma cell line. J Cell Sci. 1994; 107(pt 5):1277-1287. [PubMed: 7929634]

8. Bergkvist GT, Argyle DJ, Pang LY, et al. Studies on the inhibition of feline EGFR in squamous cell carcinoma: enhancement of radiosensitivity and rescue of resistance to small molecule inhibitors. Cancer Biol Ther. 2011; 11(11):927-937. [PubMed: 21464610]

9. Bertone ER, Snyder LA, Moore AS. Environmental and lifestyle risk factors for oral squamous cell carcinoma in domestic cats. J Vet Intern Med. 2003; 17(4):557-562. [PubMed: 12892308]

10. Blomme EA, Dougherty KM, Pienta KJ, et al. Skeletal metastasis of prostate adenocarcinoma in rats: morphometric analysis and role of parathyroid hormone-related protein. Prostate. 1999; 39(3):187-197. [PubMed: 10334108]

11. Blouin S, Basle MF, Chappard D. Rat models of bone metastases. Clin Exp Metastasis. 2005; 22(8):605-614. [PubMed: 16670964]

12. Boyce BF, Xing L. Biology of RANK, RANKL, and osteoprotegerin. Arthritis Res Ther. 2007; 9(suppl 1):S1. [PubMed: 17634140]

13. Cardiff RD, Anver MR, Gusterson BA, et al. The mammary pathology of genetically engineered mice: the consensus report and recommendations from the Annapolis meeting. Oncogene. 2000; 19(8):968-988. [PubMed: 10713680]

14. Chaffer CL, Brennan JP, Slavin JL, et al. Mesenchymal-to-epithelial transition facilitates bladder cancer metastasis: role of fibroblast growth factor receptor-2. Cancer Res. 2006; 66(23):1127111278. [PubMed: 17145872]

15. Chaffer CL, Dopheide B, McCulloch DR, et al. Upregulated MT1-MMP/TIMP-2 axis in the TSUPr1-B1/B2 model of metastatic progression in transitional cell carcinoma of the bladder. Clin Exp Metastasis. 2005; 22(2):115-125. [PubMed: 16086232]

16. Chan CM, Jing X, Pike LA, et al. Targeted inhibition of Src kinase with dasatinib blocks thyroid cancer growth and metastasis. Clin Cancer Res. 2012; 18(13):3580-3591. [PubMed: 22586301]

17. Coleman RE. Clinical features of metastatic bone disease and risk of skeletal morbidity. Clin Cancer Res. 2006; 12(20, pt 2):6243s-6249s. [PubMed: 17062708]

18. Coleman RE. Metastatic bone disease: clinical features, pathophysiology and treatment strategies. Cancer Treat Rev. 2001; 27(3):165-176. [PubMed: 11417967] 
19. Corey E, Quinn JE, Bladou F, et al. Establishment and characterization of osseous prostate cancer models: intra-tibial injection of human prostate cancer cells. Prostate. 2002; 52(1):20-33. [PubMed: 11992617]

20. Cossigny D, Quan GM. In vivo animal models of spinal metastasis. Cancer Metastasis Rev. 2012; 31(1-2):99-108. [PubMed: 22090011]

21. Cowey S, Szafran AA, Kappes J, et al. Breast cancer metastasis to bone: evaluation of bioluminescent imaging and microSPECT/CT for detecting bone metastasis in immunodeficient mice. Clin Exp Metastasis. 2007; 24(5):389-401. [PubMed: 17541709]

22. Croese JW, Vas Nunes CM, Radl J, et al. The $5 \mathrm{~T} 2$ mouse multiple myeloma model: characterization of 5T2 cells within the bone marrow. Br J Cancer. 1987; 56(5):555-560. [PubMed: 3426918]

23. Dhawan D, Ramos-Vara JA, Stewart JC, et al. Canine invasive transitional cell carcinoma cell lines: in vitro tools to complement a relevant animal model of invasive urinary bladder cancer. Urol Oncol. 2009; 27(3):284-292. [PubMed: 18562222]

24. Dinney CP, Fishbeck R, Singh RK, et al. Isolation and characterization of metastatic variants from human transitional cell carcinoma passaged by orthotopic implantation in athymic nude mice. $\mathrm{J}$ Urol. 1995; 154(4):1532-1538. [PubMed: 7658585]

25. Dore-Savard L, Barriere DA, Midavaine E, et al. Mammary cancer bone metastasis follow-up using multimodal small-animal MR and PET imaging. J Nucl Med. 2013; 54(6):944-952. [PubMed: 23596003]

26. Driessens MH, Stroeken PJ, Rodriguez Erena NF, et al. Targeted disruption of CD44 in MDAYD2 lymphosarcoma cells has no effect on subcutaneous growth or metastatic capacity. J Cell Biol. 1995; 131(6, pt 2):1849-1855. [PubMed: 8557751]

27. Durr HR, Maier M, Pfahler M, et al. Surgical treatment of osseous metastases in patients with renal cell carcinoma. Clin Orthop Relat Res. 1999; (367):283-290. [PubMed: 10546626]

28. Elkin M, Vlodavsky I. Tail vein assay of cancer metastasis. Curr Protoc Cell Biol. 2001 Chapter 19:Unit 19.2.

29. Feeley BT, Liu NQ, Conduah AH, et al. Mixed metastatic lung cancer lesions in bone are inhibited by noggin overexpression and Rank:Fc administration. J Bone Miner Res. 2006; 21(10):15711580. [PubMed: 16995812]

30. Fidler IJ. The pathogenesis of cancer metastasis: the 'seed and soil' hypothesis revisited. Nat Rev Cancer. 2003; 3(6):453-458. [PubMed: 12778135]

31. Foley J, Nickerson N, Riese DJ II, et al. At the crossroads: EGFR and PTHrP signaling in cancermediated diseases of bone. Odontology. 2012; 100(2):109-129. [PubMed: 22684584]

32. Gao L, Deng H, Zhao H, et al. HTLV-1 Tax transgenic mice develop spontaneous osteolytic bone metastases prevented by osteoclast inhibition. Blood. 2005; 106(13):4294-4302. [PubMed: 16118323]

33. Gardner DG. Spontaneous squamous cell carcinomas of the oral region in domestic animals: a review and consideration of their relevance to human research. Oral Dis. 1996; 2(2):148-154. [PubMed: 8957928]

34. Geldof AA, Rao BR. Prostatic tumor (R3327) skeletal metastasis. Prostate. 1990; 16(4):279-290. [PubMed: 2371174]

35. Gingrich JR, Barrios RJ, Morton RA, et al. Metastatic prostate cancer in a transgenic mouse. Cancer Res. 1996; 56(18):4096-4102. [PubMed: 8797572]

36. Goldman SM, Fajardo AA, Naraval RC, et al. Metastatic transitional cell carcinoma from the bladder: radiographic manifestations. AJR Am J Roentgenol. 1979; 132(3):419-425. [PubMed: 106647]

37. Gupta S, Hastak K, Ahmad N, et al. Inhibition of prostate carcinogenesis in TRAMP mice by oral infusion of green tea polyphenols. Proc Natl Acad Sci U S A. 2001; 98(18):10350-10355. [PubMed: 11504910]

38. Hai J, Zhu CQ, Bandarchi B, et al. L1 cell adhesion molecule promotes tumorigenicity and metastatic potential in non-small cell lung cancer. Clin Cancer Res. 2012; 18(7):1914-1924. [PubMed: 22307136] 
39. Hall DG, Stoica G. Effect of the bisphosphonate risedronate on bone metastases in a rat mammary adenocarcinoma model system. J Bone Miner Res. 1994; 9(2):221-230. [PubMed: 8140935]

40. Halvorson KG, Kubota K, Sevcik MA, et al. A blocking antibody to nerve growth factor attenuates skeletal pain induced by prostate tumor cells growing in bone. Cancer Res. 2005; 65(20):94269435. [PubMed: 16230406]

41. Halvorson KG, Sevcik MA, Ghilardi JR, et al. Similarities and differences in tumor growth, skeletal remodeling and pain in an osteolytic and osteoblastic model of bone cancer. Clin J Pain. 2006; 22(7):587-600. [PubMed: 16926574]

42. Haq M, Goltzman D, Tremblay G, et al. Rat prostate adenocarcinoma cells disseminate to bone and adhere preferentially to bone marrow-derived endothelial cells. Cancer Res. 1992; 52(17): 4613-4619. [PubMed: 1511429]

43. Hawley TS, Lach B, Burns BF, et al. Expression of retrovirally transduced IL-1 alpha in IL-6dependent B cells: a murine model of aggressive multiple myeloma. Growth Factors. 1991; 5(4): 327-338. [PubMed: 1777241]

44. Heidenreich A. Bisphosphonates in the management of metastatic prostate cancer. Oncology. 2003; 65(suppl 1):5-11. [PubMed: 12949427]

45. Hensley PJ, Kyprianou N. Modeling prostate cancer in mice: limitations and opportunities. J Androl. 2012; 33(2):133-144. [PubMed: 21680808]

46. Hiraoka K, Zenmyo M, Watari K, et al. Inhibition of bone and muscle metastases of lung cancer cells by a decrease in the number of monocytes/macrophages. Cancer Sci. 2008; 99(8):1595-1602. [PubMed: 18754872]

47. Hoffman RM. Orthotopic metastatic mouse models for anticancer drug discovery and evaluation: a bridge to the clinic. Invest New Drugs. 1999; 17(4):343-359. [PubMed: 10759402]

48. Hwang YS, Zhang X, Park KK, et al. An orthotopic and osteolytic model with a newly established oral squamous cell carcinoma cell line. Arch Oral Biol. 2013; 58(2):218-225. [PubMed: 22621906]

49. Inoue K, Karashima T, Fukata S, et al. Effect of combination therapy with a novel bisphosphonate, minodronate (YM529), and docetaxel on a model of bone metastasis by human transitional cell carcinoma. Clin Cancer Res. 2005; 11(18):6669-6677. [PubMed: 16166446]

50. Ip C. Mammary tumorigenesis and chemoprevention studies in carcinogen-treated rats. J Mammary Gland Biol. 1996; 1(1):37-47.

51. Jang BS. MicroSPECT and MicroPET imaging of small animals for drug development. Toxicol Res. 2013; 29(1):1-6. [PubMed: 24278622]

52. Jimi E, Shin M, Furuta H, et al. The RANKL/RANK system as a therapeutic target for bone invasion by oral squamous cell carcinoma. Int J Oncol. 2013; 42(3):803-809. [PubMed: 23354319]

53. Karam JA, Mason RP, Koeneman KS, et al. Molecular imaging in prostate cancer. J Cell Biochem. 2003; 90(3):473-483. [PubMed: 14523981]

54. Kasper S. Survey of genetically engineered mouse models for prostate cancer: analyzing the molecular basis of prostate cancer development, progression, and metastasis. J Cell Biochem. 2005; 94(2):279-297. [PubMed: 15565647]

55. Keller JM, Schade GR, Ives K, et al. A novel canine model for prostate cancer. Prostate. 2013; 73(9):952-959. [PubMed: 23335024]

56. Khanna C, Lindblad-Toh K, Vail D, et al. The dog as a cancer model. Nat Biotechnol. 2006; 24(9): 1065-1066. [PubMed: 16964204]

57. Kim S. Animal models of cancer in the head and neck region. Clin Exp Otorhinolaryngol. 2009; 2(2):55-60. [PubMed: 19565028]

58. Knapp DW, Glickman NW, Denicola DB, et al. Naturally-occurring canine transitional cell carcinoma of the urinary bladder: a relevant model of human invasive bladder cancer. Urol Oncol. 2000; 5(2):47-59. [PubMed: 21227289]

59. Koba W, Jelicks LA, Fine EJ. MicroPET/SPECT/CT imaging of small animal models of disease. Am J Pathol. 2013; 182(2):319-324. [PubMed: 23219729]

60. Koutsilieris M. PA-III rat prostate adenocarcinoma cells. In Vivo. 1992; 6(2):199-203. [PubMed: 1326342] 
61. Kovalchuk AL, Qi CF, Torrey TA, et al. Burkitt lymphoma in the mouse. J Exp Med. 2000; 192(8):1183-1190. [PubMed: 11034608]

62. Lacroix M. MDA-MB-435 cells are from melanoma, not from breast cancer. Cancer Chemother Pharmacol. 2009; 63(3):567. [PubMed: 18500520]

63. Langlais LM, Gibson J, Taylor JA, et al. Pulmonary adenocarcinoma with metastasis to skeletal muscle in a cat. Can Vet J. 2006; 47(11):1122-1123. [PubMed: 17147146]

64. Lee YP, Schwarz EM, Davies M, et al. Use of zoledronate to treat osteoblastic versus osteolytic lesions in a severe-combined-immunodeficient mouse model. Cancer Res. 2002; 62(19):55645570. [PubMed: 12359769]

65. Lelekakis M, Moseley JM, Martin TJ, et al. A novel orthotopic model of breast cancer metastasis to bone. Clin Exp Metastasis. 1999; 17(2):163-170. [PubMed: 10411109]

66. LeRoy BE, Northrup N. Prostate cancer in dogs: comparative and clinical aspects. Vet J. 2009; 180(2):149-162. [PubMed: 18786842]

67. LeRoy BE, Thudi NK, Nadella MV, et al. New bone formation and osteolysis by a metastatic, highly invasive canine prostate carcinoma xenograft. Prostate. 2006; 66(11):1213-1222. [PubMed: 16683269]

68. Li X, Liao J, Park SI, et al. Drugs which inhibit osteoclast function suppress tumor growth through calcium reduction in bone. Bone. 2011; 48(6):1354-1361. [PubMed: 21419883]

69. Liao J, Li X, Koh AJ, et al. Tumor expressed PTHrP facilitates prostate cancer-induced osteoblastic lesions. Int J Cancer. 2008; 123(10):2267-2278. [PubMed: 18729185]

70. Liepe K, Geidel H, Haase M, et al. New model for the induction of osteoblastic bone metastases in rat. Anticancer Res. 2005; 25(2A):1067-1073. [PubMed: 15868947]

71. Liu J, Blackhall F, Seiden-Long I, et al. Modeling of lung cancer by an orthotopically growing H460SM variant cell line reveals novel candidate genes for systemic metastasis. Oncogene. 2004; 23(37):6316-6324. [PubMed: 15247903]

72. Lu SL, Herrington H, Wang XJ. Mouse models for human head and neck squamous cell carcinomas. Head Neck. 2006; 28(10):945-954. [PubMed: 16721744]

73. MacEwen EG. Spontaneous tumors in dogs and cats: models for the study of cancer biology and treatment. Cancer Metastasis Rev. 1990; 9(2):125-136. [PubMed: 2253312]

74. Malek S, Murphy KA, Nykamp SG, et al. Metastatic transitional cell carcinoma in proximal humerus of a dog. Can Vet J. 2011; 52(9):1013-1017. [PubMed: 22379204]

75. Martin CK, Dirksen WP, Shu ST, et al. Characterization of bone resorption in novel in vitro and in vivo models of oral squamous cell carcinoma. Oral Oncol. 2012; 48(6):491-499. [PubMed: 22265717]

76. Martin CK, Tannehill-Gregg SH, Wolfe TD, et al. Bone-invasive oral squamous cell carcinoma in cats: pathology and expression of parathyroid hormone-related protein. Vet Pathol. 2011; 48(1): 302-312. [PubMed: 20940448]

77. Martin CK, Werbeck JL, Thudi NK, et al. Zoledronic acid reduces bone loss and tumor growth in an orthotopic xenograft model of osteolytic oral squamous cell carcinoma. Cancer Res. 2010; 70(21):8607-8616. [PubMed: 20959474]

78. Masood R, Hochstim C, Cervenka B, et al. A novel orthotopic mouse model of head and neck cancer and lymph node metastasis. Oncogenesis. 2013; 2:e68. [PubMed: 24018643]

79. Medhurst SJ, Walker K, Bowes M, et al. A rat model of bone cancer pain. Pain. 2002; 96(1-2): 129-140. [PubMed: 11932069]

80. Mehra R, Kumar-Sinha C, Shankar S, et al. Characterization of bone metastases from rapid autopsies of prostate cancer patients. Clin Cancer Res. 2011; 17(12):3924-3932. [PubMed: 21555375]

81. Meuten DJ, Kociba GJ, Capen CC, et al. Hypercalcemia in dogs with lymphosarcoma. Biochemical, ultrastructural, and histomorphometric investigations. Lab Invest. 1983; 49(5):553562. [PubMed: 6314038]

82. Michigami T, Nomizu M, Yamada Y, et al. Growth and dissemination of a newly-established murine B-cell lymphoma cell line is inhibited by multimeric YIGSR peptide. Clin Exp Metastasis. 1998; 16(7):645-654. [PubMed: 9932611] 
83. Miki T, Yano S, Hanibuchi M, et al. Parathyroid hormone-related protein (PTHrP) is responsible for production of bone metastasis, but not visceral metastasis, by human small cell lung cancer SBC-5 cells in natural killer cell-depleted SCID mice. Int J Cancer. 2004; 108(4):511-515. [PubMed: 14696114]

84. Miki T, Yano S, Hanibuchi M, et al. Bone metastasis model with multiorgan dissemination of human small-cell lung cancer (SBC-5) cells in natural killer cell-depleted SCID mice. Oncol Res. 2000; 12(5):209-217. [PubMed: 11417746]

85. Mizutani R, Suzuki Y. X-ray microtomography in biology. Micron. 2012; 43(2-3):104-115. [PubMed: 22036251]

86. Mueller-Klieser W, Schaefer C, Walenta S, et al. Assessment of tumor energy and oxygenation status by bioluminescence, nuclear magnetic resonance spectroscopy, and cryospectrophotometry. Cancer Res. 1990; 50(6):1681-1685. [PubMed: 2306721]

87. Mundy G. Preclinical models of bone metastases. Semin Oncol. 2001; 28(4 suppl 11):2-8. [PubMed: 11544569]

88. Nadella MV, Kisseberth WC, Nadella KS, et al. NOD/SCID mouse model of canine T-cell lymphoma with humoral hypercalcaemia of malignancy: cytokine gene expression profiling and in vivo bioluminescent imaging. Vet Comp Oncol. 2008; 6(1):39-54. [PubMed: 19178662]

89. Nakano T, Shimizu K, Kawashima O, et al. Establishment of a human lung cancer cell line with high metastatic potential to multiple organs: gene expression associated with metastatic potential in human lung cancer. Oncol Rep. 2012; 28(5):1727-1735. [PubMed: 22922681]

90. Nemec A, Murphy BG, Jordan RC, et al. Oral papillary squamous cell carcinoma in twelve dogs. J Comp Pathol. 2014; 150(2-3):155-161. [PubMed: 24016780]

91. Nemeth JA, Harb JF, Barroso U Jr, et al. Severe combined immunodeficient-hu model of human prostate cancer metastasis to human bone. Cancer Res. 1999; 59(8):1987-1993. [PubMed: 10213511]

92. Ng CS, Wood CG, Silverman PM, et al. Renal cell carcinoma: diagnosis, staging, and surveillance. Am J Roentgenol. 2008; 191(4):1220-1232. [PubMed: 18806169]

93. Ooi LL, Zheng Y, Zhou H, et al. Vitamin D deficiency promotes growth of MCF-7 human breast cancer in a rodent model of osteosclerotic bone metastasis. Bone. 2010; 47(4):795-803. [PubMed: 20638491]

94. Padalecki SS, Guise TA. Actions of bisphosphonates in animal models of breast cancer. Breast Cancer Res. 2002; 4(1):35-41. [PubMed: 11879558]

95. Paget S. The distribution of secondary growths in cancer of the breast. Lancet. 1889; 1:571-573.

96. Paoloni M, Khanna C. Translation of new cancer treatments from pet dogs to humans. Nat Rev Cancer. 2008; 8(2):147-156. [PubMed: 18202698]

97. Paulussen M, Ahrens S, Burdach S, et al. Primary metastatic (stage IV) Ewing tumor: survival analysis of 171 patients from the EICESS studies. European Intergroup Cooperative Ewing Sarcoma Studies. Ann Oncol. 1998; 9(3):275-281. [PubMed: 9602261]

98. Paulussen M, Ahrens S, Craft AW, et al. Ewing's tumors with primary lung metastases: survival analysis of 114 (European Intergroup) Cooperative Ewing's Sarcoma Studies patients. J Clin Oncol. 1998; 16(9):3044-3052. [PubMed: 9738574]

99. Paulussen M, Ahrens S, Dunst J, et al. Localized Ewing tumor of bone: final results of the cooperative Ewing's Sarcoma Study CESS 86. J Clin Oncol. 2001; 19(6):1818-1829. [PubMed: 11251014]

100. Pilarski LM, Hipperson G, Seeberger K, et al. Myeloma progenitors in the blood of patients with aggressive or minimal disease: engraftment and self-renewal of primary human myeloma in the bone marrow of NOD SCID mice. Blood. 2000; 95(3):1056-1065. [PubMed: 10648422]

101. Radl J, Croese JW, Zurcher C, et al. Animal model of human disease: multiple myeloma. Am J Pathol. 1988; 132(3):593-597. [PubMed: 3414786]

102. Radl J, De Glopper ED, Schuit HR, et al. Idiopathic paraproteinemia: II. Transplantation of the paraprotein-producing clone from old to young C57BL/KaLwRij mice. J Immunol. 1979; 122(2): 609-613. [PubMed: 368243] 
103. Rathore K, Alexander M, Cekanova M. Piroxicam inhibits masitinib-induced cyclooxygenase 2 expression in oral squamous cell carcinoma cells in vitro. Transl Res. 2014; 164(2):158-168. [PubMed: 24631063]

104. Richard V, Lairmore MD, Green PL, et al. Humoral hypercalcemia of malignancy: severe combined immunodeficient/beige mouse model of adult T-cell lymphoma independent of human T-cell lymphotropic virus type-1 tax expression. Am J Pathol. 2001; 158(6):2219-2228. [PubMed: 11395400]

105. Roato I, Caldo D, Godio L, et al. Bone invading NSCLC cells produce IL-7: mice model and human histologic data. BMC Cancer. 2010; 10:12. [PubMed: 20067635]

106. Rosol TJ. Pathogenesis of bone metastases: role of tumor-related proteins. J Bone Miner Res. 2000; 15(5):844-850. [PubMed: 10804013]

107. Rosol TJ, Capen CC. Pathogenesis of humoral hypercalcemia of malignancy. Domest Anim Endocrinol. 1988; 5(1):1-21. [PubMed: 3066580]

108. Rosol TJ, Tannehill-Gregg SH, Corn S, et al. Animal models of bone metastasis. Cancer Treat Res. 2004; 118:47-81. [PubMed: 15043188]

109. Rosol TJ, Tannehill-Gregg SH, LeRoy BE, et al. Animal models of bone metastasis. Cancer. 2003; 97:748-757. [PubMed: 12548572]

110. Roth ES, Fetzer DT, Barron BJ, et al. Does colon cancer ever metastasize to bone first? A temporal analysis of colorectal cancer progression. BMC Cancer. 2009; 9:274. [PubMed: 19664211]

111. Rothenberg SM, Ellisen LW. The molecular pathogenesis of head and neck squamous cell carcinoma. J Clin Invest. 2012; 122(6):1951-1957. [PubMed: 22833868]

112. Roy-Burman P, Wu H, Powell WC, et al. Genetically defined mouse models that mimic natural aspects of human prostate cancer development. Endocr Relat Cancer. 2004; 11(2):225-254. [PubMed: 15163300]

113. Ruegemer JJ, Hay ID, Bergstralh EJ, et al. Distant metastases in differentiated thyroid carcinoma: a multivariate analysis of prognostic variables. J Clin Endocrinol Metab. 1988; 67(3):501-508. [PubMed: 3410936]

114. Sakaguchi S, Goto H, Hanibuchi M, et al. Gender difference in bone metastasis of human small cell lung cancer, SBC-5 cells in natural killer-cell depleted severe combined immunodeficient mice. Clin Exp Metastasis. 2010; 27(5):351-359. [PubMed: 20464627]

115. Santini D, Galluzzo S, Zoccoli A, et al. New molecular targets in bone metastases. Cancer Treat Rev. 2010; 36(suppl 3):S6-S10. [PubMed: 21129612]

116. Schade GR, Keller J, Ives K, et al. Histotripsy focal ablation of implanted prostate tumor in an ACE-1 canine cancer model. J Urol. 2012; 188(5):1957-1964. [PubMed: 22999534]

117. Schlumberger M, Tubiana M, De Vathaire F, et al. Long-term results of treatment of 283 patients with lung and bone metastases from differentiated thyroid carcinoma. J Clin Endocrinol Metab. 1986; 63(4):960-967. [PubMed: 3745409]

118. Scotlandi K, Benini S, Manara MC, et al. Murine model for skeletal metastases of Ewing's sarcoma. J Orthop Res. 2000; 18(6):959-966. [PubMed: 11192257]

119. Seely, JC.; Boorman, GA. Mammaryglandandspecializedsebaceous glands. In: Maronpot, RR.; Boorman, GA.; Gaul, BW., editors. Pathology of the Mouse. Vienna, IL: Cache River Press; 1999. p. 613-636.

120. Shu ST, Nadella MV, Dirksen WP, et al. A novel bioluminescent mouse model and effective therapy for adult T-cell leukemia/lymphoma. Cancer Res. 2007; 67(24):11859-11866. [PubMed: 18089816]

121. Siegel R, Naishadham D, Jemal A. Cancer statistics, 2013. CA Cancer J Clin. 2013; 63(1):11-30. [PubMed: 23335087]

122. Simmons JK, Dirksen WP, Hildreth BE III, et al. Canine prostate cancer cell line (Probasco) produces osteoblastic metastases in vivo. Prostate. 2014; 74(13):1251-1265. [PubMed: 25043424]

123. Simmons JK, Elshafae SM, Keller ET, et al. Review of animal models of prostate cancer bone metastasis. Vet Sci. 2014; 1(1):16-39. 
124. Singh AS, Figg WD. In vivo models of prostate cancer metastasis to bone. J Urol. 2005; 174(3): 820-826. [PubMed: 16093963]

125. Smith LP, Thomas GR. Animal models for the study of squamous cell carcinoma of the upper aerodigestive tract: a historical perspective with review of their utility and limitations. Part A. Chemically-induced de novo cancer, syngeneic animal models of HNSCC, animal models of transplanted xenogeneic human tumors. Int J Cancer. 2006; 118(9):2111-2122. [PubMed: 16380986]

126. Snyder LA, Bertone ER, Jakowski RM, et al. p53 expression and environmental tobacco smoke exposure in feline oral squamous cell carcinoma. Vet Pathol. 2004; 41(3):209-214. [PubMed: 15133168]

127. Soltero-Rivera MM, Krick EL, Reiter AM, et al. Prevalence of regional and distant metastasis in cats with advanced oral squamous cell carcinoma: 49 cases (2005-2011). J Feline Med Surg. 2014; 16(2):164-169. [PubMed: 24027053]

128. Soodgupta D, Hurchla MA, Jiang M, et al. Very late antigen-4 (alpha(4)beta(1) Integrin) targeted PET imaging of multiple myeloma. PLoS One. 2013; 8(2):e55841. [PubMed: 23409060]

129. Stoica G, Koestner A, Capen CC. Characterization of N-ethyl-N-nitrosourea-induced mammary tumors in the rat. Am J Pathol. 1983; 110(2):161-169. [PubMed: 6824063]

130. Stoica G, Koestner A, Capen CC. Neoplasms induced with high single doses of N-ethyl-Nnitrosourea in 30-day-old Sprague-Dawley rats, with special emphasis on mammary neoplasia. Anticancer Res. 1984; 4(1-2):5-12. [PubMed: 6712176]

131. Strube A, Stepina E, Mumberg D, et al. Characterization of a new renal cell carcinoma bone metastasis mouse model. Clin Exp Metastasis. 2010; 27(5):319-330. [PubMed: 20443133]

132. Sturge J, Caley MP, Waxman J. Bone metastasis in prostate cancer: emerging therapeutic strategies. Nat Rev Clin Oncol. 2011; 8(6):357-368. [PubMed: 21556025]

133. Takayama Y, Mori T, Nomura T, et al. Parathyroid-related protein plays a critical role in bone invasion by oral squamous cell carcinoma. Int J Oncol. 2010; 36(6):1387-1394. [PubMed: 20428761]

134. Tannehill-Gregg S, Kergosien E, Rosol TJ. Feline head and neck squamous cell carcinoma cell line: characterization, production of parathyroid hormone-related protein, and regulation by transforming growth factor-beta. In Vitro Cell Dev Biol Anim. 2001; 37(10):676-683. [PubMed: 11776973]

135. Tannehill-Gregg SH, Levine AL, Nadella MV, et al. The effect of zoledronic acid and osteoprotegerin on growth of human lung cancer in the tibias of nude mice. Clin Exp Metastasis. 2006; 23(1):19-31. [PubMed: 16715352]

136. Tannehill-Gregg SH, Levine AL, Rosol TJ. Feline head and neck squamous cell carcinoma: a natural model for the human disease and development of a mouse model. Vet Comp Oncol. 2006; 4(2):84-97. [PubMed: 19754818]

137. Tatsui CE, Lang FF, Gumin J, et al. An orthotopic murine model of human spinal metastasis: histological and functional correlations. J Neurosurg Spine. 2009; 10(6):501-512. [PubMed: 19558282]

138. Taube T, Beneton MN, McCloskey EV, et al. Abnormal bone remodelling in patients with myelomatosis and normal biochemical indices of bone resorption. Eur J Haematol. 1992; 49(4): 192-198. [PubMed: 1464362]

139. Tennant TR, Kim H, Sokoloff M, et al. The Dunning model. Prostate. 2000; 43(4):295-302. [PubMed: 10861749]

140. Thompson TC, Park SH, Timme TL, et al. Loss of p53 function leads to metastasis in ras+mycinitiated mouse prostate cancer. Oncogene. 1995; 10(5):869-879. [PubMed: 7534899]

141. Thudi NK, Martin CK, Murahari S, et al. Dickkopf-1 (DKK-1) stimulated prostate cancer growth and metastasis and inhibited bone formation in osteoblastic bone metastases. Prostate. 2011; 71(6):615-625. [PubMed: 20957670]

142. Thudi NK, Martin CK, Nadella MV, et al. Zoledronic acid decreased osteolysis but not bone metastasis in a nude mouse model of canine prostate cancer with mixed bone lesions. Prostate. 2008; 68(10):1116-1125. [PubMed: 18461562] 
143. Thudi NK, Shu ST, Martin CK, et al. Development of a brain metastatic canine prostate cancer cell line. Prostate. 2011; 71(12):1251-1263. [PubMed: 21321976]

144. Tomasoni A, Scanziani E, Massazza G, et al. Organ-specific growth of a murine lymphoma of spontaneous origin in nude mice. Clin Exp Metastasis. 1991; 9(5):485-497. [PubMed: 1914281]

145. Trost ME, Inkelmann MA, Galiza GJ, et al. Occurrence of tumours metastatic to bones and multicentric tumours with skeletal involvement in dogs. J Comp Pathol. 2014; 150(1):8-17. [PubMed: 24011903]

146. Uccella S, Morris JM, Bakkum-Gamez JN, et al. Bone metastases in endometrial cancer: report on 19 patients and review of the medical literature. Gynecol Oncol. 2013; 130(3):474-482. [PubMed: 23685013]

147. Ukpo OC, Flanagan JJ, Ma XJ, et al. High-risk human papillomavirus E6/E7 mRNA detection by a novel in situ hybridization assay strongly correlates with p16 expression and patient outcomes in oropharyngeal squamous cell carcinoma. Am J Pathol. 2011; 35(9):1343-1350.

148. Urashima M, Chen BP, Chen S, et al. The development of a model for the homing of multiple myeloma cells to human bone marrow. Blood. 1997; 90(2):754-765. [PubMed: 9226176]

149. Valero C, Olmos JM, Rivera F, et al. Osteoprotegerin and bone mass in squamous cell head and neck cancer patients. Calcif Tissue Int. 2006; 78(6):343-347. [PubMed: 16830204]

150. Valkenburg KC, Williams BO. Mouse models of prostate cancer. Prostate Cancer. 2011; 2011:895238. [PubMed: 22111002]

151. Valta MP, Zhao H, Ingels A, et al. Development of a realistic in vivo bone metastasis model of human renal cell carcinoma. Clin Exp Metastasis. 2014; 31(5):573-584. [PubMed: 24715498]

152. van Bokhoven A, Varella-Garcia M, Korch C, et al. TSU-Pr1 and JCA-1 cells are derivatives of T24 bladder carcinoma cells and are not of prostatic origin. Cancer Res. 2001; 61(17):6340_ 6344. [PubMed: 11522622]

153. van der Horst G, van Asten JJ, Figdor A, et al. Real-time cancer cell tracking by bioluminescence in a preclinical model of human bladder cancer growth and metastasis. Eur Urol. 2011; 60(2): 337-343. [PubMed: 21616583]

154. Van Valckenborgh E, Croucher PI, De Raeve H, et al. Multifunctional role of matrix metalloproteinases in multiple myeloma: a study in the 5T2MM mouse model. Am J Pathol. 2004; 165(3):869-878. [PubMed: 15331411]

155. van Valen F, Winkelmann W, Jurgens H. Type I and type II insulin-like growth factor receptors and their function in human Ewing's sarcoma cells. J Cancer Res Clin Oncol. 1992; 118(4):269275. [PubMed: 1315779]

156. Vormoor B, Knizia HK, Batey MA, et al. Development of a preclinical orthotopic xenograft model of ewing sarcoma and other human malignant bone disease using advanced in vivo imaging. PLoS One. 2014; 9(1):e85128. [PubMed: 24409320]

157. Vormoor J, Baersch G, Decker S, et al. Establishment of an in vivo model for pediatric Ewing tumors by transplantation into NOD/scid mice. Pediatr Res. 2001; 49(3):332-341. [PubMed: 11228258]

158. Wallmeroth A, Wagner U, Moch H, et al. Patterns of metastasis in muscle-invasive bladder cancer (pT2-4): an autopsy study on 367 patients. Urol Int. 1999; 62(2):69-75. [PubMed: 10461106]

159. Wang J, Chen A, Yang C, et al. A bone-seeking clone exhibits different biological properties from the ACHN parental human renal cell carcinoma in vivo and in vitro. Oncol Rep. 2012; 27(4):1104-1110. [PubMed: 22139406]

160. Wang YX, Mandal D, Wang S, et al. Inhibiting platelet-derived growth factor beta reduces Ewing's sarcoma growth and metastasis in a novel orthotopic human xenograft model. In vivo. 2009; 23(6):903-909. [PubMed: 20023231]

161. Warnke RA, Slavin S, Coffman RL, et al. The pathology and homing of a transplantable murine B cell leukemia (BCL1). J Immunol. 1979; 123(3):1181-1188. [PubMed: 381519]

162. Weber KL, Pathak S, Multani AS, et al. Characterization of a renal cell carcinoma cell line derived from a human bone metastasis and establishment of an experimental nude mouse model. J Urol. 2002; 168(2):774-779. [PubMed: 12131367] 
163. Weilbaecher KN, Guise TA, McCauley LK. Cancer to bone: a fatal attraction. Nat Rev Cancer. 2011; 11(6):411-425. [PubMed: 21593787]

164. Werbeck JL, Thudi NK, Martin CK, et al. Tumor microenvironment regulates metastasis and metastasis genes of mouse MMTV-PymT mammary cancer cells in vivo. Vet Pathol. 2013; 51(4):868-881. [PubMed: 24091811]

165. Wetterwald A, van der Pluijm G, Que I, et al. Optical imaging of cancer metastasis to bone marrow: a mouse model of minimal residual disease. Am J Pathol. 2002; 160(3):1143-1153. [PubMed: 11891210]

166. Whang-Peng J, Triche TJ, Knutsen T, et al. Chromosome translocation in peripheral neuroepithelioma. N Engl J Med. 1984; 311(9):584-585. [PubMed: 6749231]

167. Wise-Milestone L, Akens MK, Rosol TJ, et al. Evaluating the effects of mixed osteolytic/ osteoblastic metastasis on vertebral bone quality in a new rat model. J Orthop Res. 2012; 30(5): 817-823. [PubMed: 22025272]

168. Wypij JM. A naturally occurring feline model of head and neck squamous cell carcinoma. Pathol Res Int. 2013; 2013:502197.

169. Yang J, Fizazi K, Peleg S, et al. Prostate cancer cells induce osteoblast differentiation through a Cbfa1-dependent pathway. Cancer Res. 2001; 61(14):5652-5659. [PubMed: 11454720]

170. Yang M, Jiang P, Sun FX, et al. A fluorescent orthotopic bone metastasis model of human prostate cancer. Cancer Res. 1999; 59(4):781-786. [PubMed: 10029062]

171. Yang S, Dong Q, Yao M, et al. Establishment of an experimental human lung adenocarcinoma cell line SPC-A-1BM with high bone metastases potency by $(99 \mathrm{~m}) \mathrm{Tc}-\mathrm{MDP}$ bone scintigraphy. Nucl Med Biol. 2009; 36(3):313-321. [PubMed: 19324277]

172. Yang Y, Macleod V, Bendre M, et al. Heparanase promotes the spontaneous metastasis of myeloma cells to bone. Blood. 2005; 105(3):1303-1309. [PubMed: 15471949]

173. Yang Y, Ren Y, Ramani VC, et al. Heparanase enhances local and systemic osteolysis in multiple myeloma by upregulating the expression and secretion of RANKL. Cancer Res. 2010; 70(21): 8329-8338. [PubMed: 20978204]

174. Yi B, Williams PJ, Niewolna M, et al. Tumor-derived platelet-derived growth factor-BB plays a critical role in osteosclerotic bone metastasis in an animal model of human breast cancer. Cancer Res. 2002; 62(3):917-923. [PubMed: 11830552]

175. Yin JJ, Mohammad KS, Kakonen SM, et al. A causal role for endothelin-1 in the pathogenesis of osteoblastic bone metastases. Proc Natl Acad Sci U S A. 2003; 100(19):10954-10959. [PubMed: 12941866]

176. Yoneda T, Michigami T, Yi B, et al. Actions of bisphosphonate on bone metastasis in animal models of breast carcinoma. Cancer. 2000; 88(12 suppl):2979-2988. [PubMed: 10898341]

177. Yonou H, Yokose T, Kamijo T, et al. Establishment of a novel species- and tissue-specific metastasis model of human prostate cancer in humanized non-obese diabetic/severe combined immunodeficient mice engrafted with human adult lung and bone. Cancer Res. 2001; 61(5): 2177-2182. [PubMed: 11280783]

178. Younes MN, Yigitbasi OG, Park YW, et al. Antivascular therapy of human follicular thyroid cancer experimental bone metastasis by blockade of epidermal growth factor receptor and vascular growth factor receptor phosphorylation. Cancer Res. 2005; 65(11):4716-4727. [PubMed: 15930290]

179. Zekri J, Ahmed N, Coleman RE, et al. The skeletal metastatic complications of renal cell carcinoma. Int J Oncol. 2001; 19(2):379-382. [PubMed: 11445855]

180. Zhang L, Gaskins K, Yu Z, et al. An in vivo mouse model of metastatic human thyroid cancer. Thyroid. 2014; 24(4):695-704. [PubMed: 24262022]

181. Zheleznyak A, Wadas TJ, Sherman CD, et al. Integrin alpha(v)-beta(3) as a PET imaging biomarker for osteoclast number in mouse models of negative and positive osteoclast regulation. Mol Imaging Biol. 2012; 14(4):500-508. [PubMed: 21853370]

182. Zygogianni AG, Kyrgias G, Karakitsos P, et al. Oral squamous cell cancer: early detection and the role of alcohol and smoking. Head Neck Oncol. 2011; 3:2. [PubMed: 21211041] 


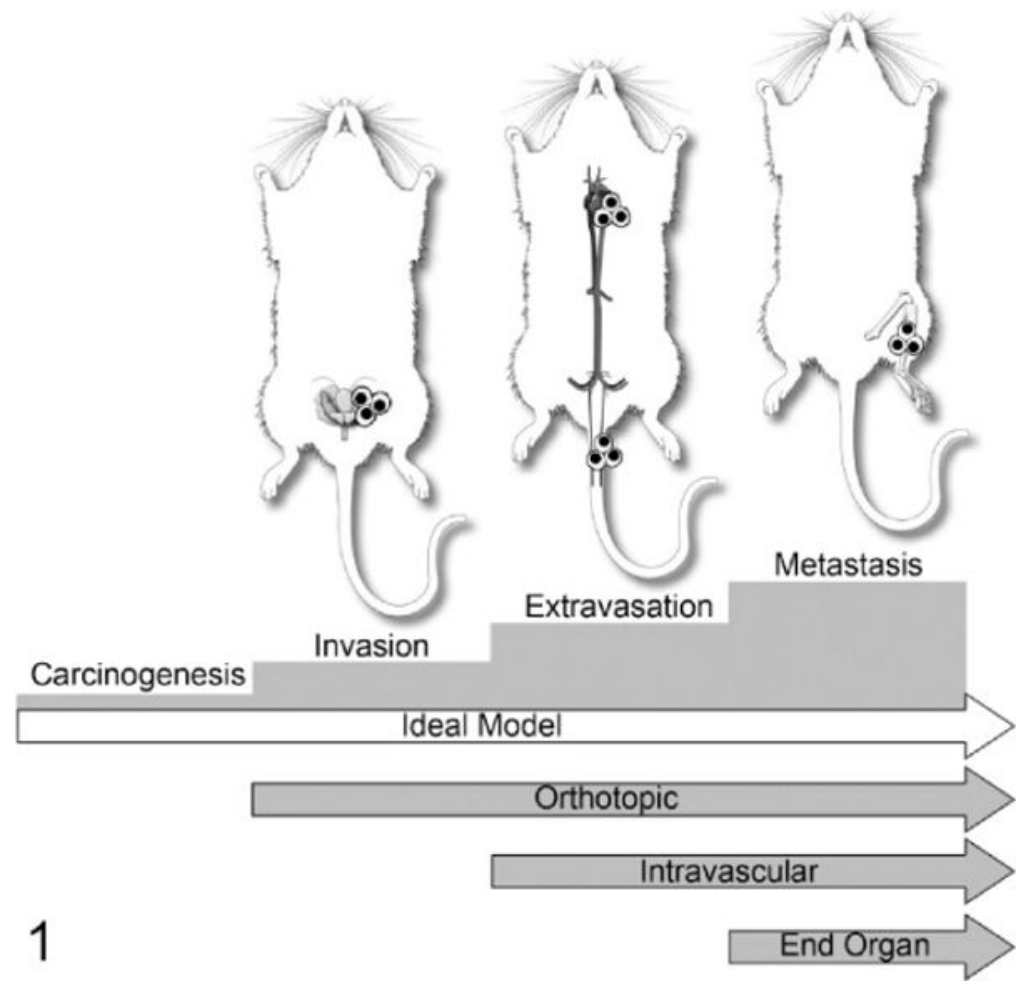

Figure 1.

Various injection models used to investigate cancer progression and metastasis. Orthotopic injections model invasion, extravasation, and distant metastasis. Intravascular injections (intracardiac, tail vein) model extravasation and metastasis. Tail vein injections tend to favor lung metastases, whereas intracardiac (left ventricular) injection permits neoplastic cells to localize to any tissue of the body depending on its inherent metastatic phenotype. Finally, intraosseous injections model the ability to grow in and modify the bone microenvironment. Reprinted from Werbeck et al. ${ }^{164}$ 


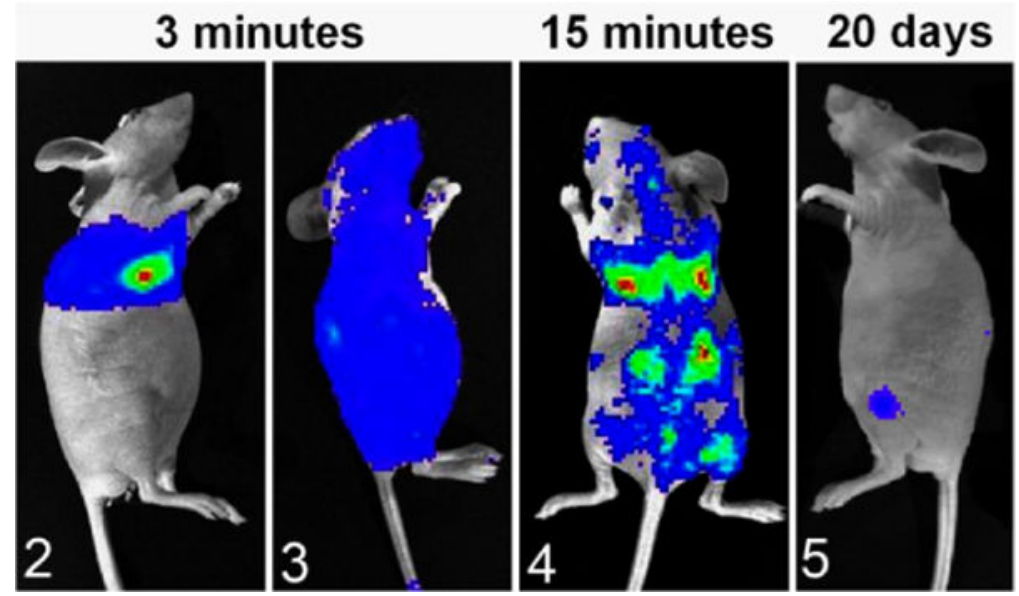

Figures 2-5.

Bioluminescent imaging of luciferase(+) canine prostate cancer cells (Ace-1) after injection of 100000 cells into the left cardiac ventricle of nude mice. Colors represent relative numbers of viable tumor cells: red $>$ yellow > green $>$ blue. Figure 2. Three minutes after injection. The mouse had an unsuccessful intracardiac injection, since Ace-1 cells were present only in the pericardial and pleural spaces. Figure 3. The mouse had a successful intracardiac injection since Ace- 1 cells were circulating throughout the body at 3 minutes after injection. Figure 4. At 15 minutes after intracardiac injection, the Ace-1 cells localized to the eyes, brain, lungs, bones, and kidneys. Figure 5. At 20 days, only 2 Ace-1-injected cells survived to form bone metastases in the left proximal tibia and dorsal spine. 


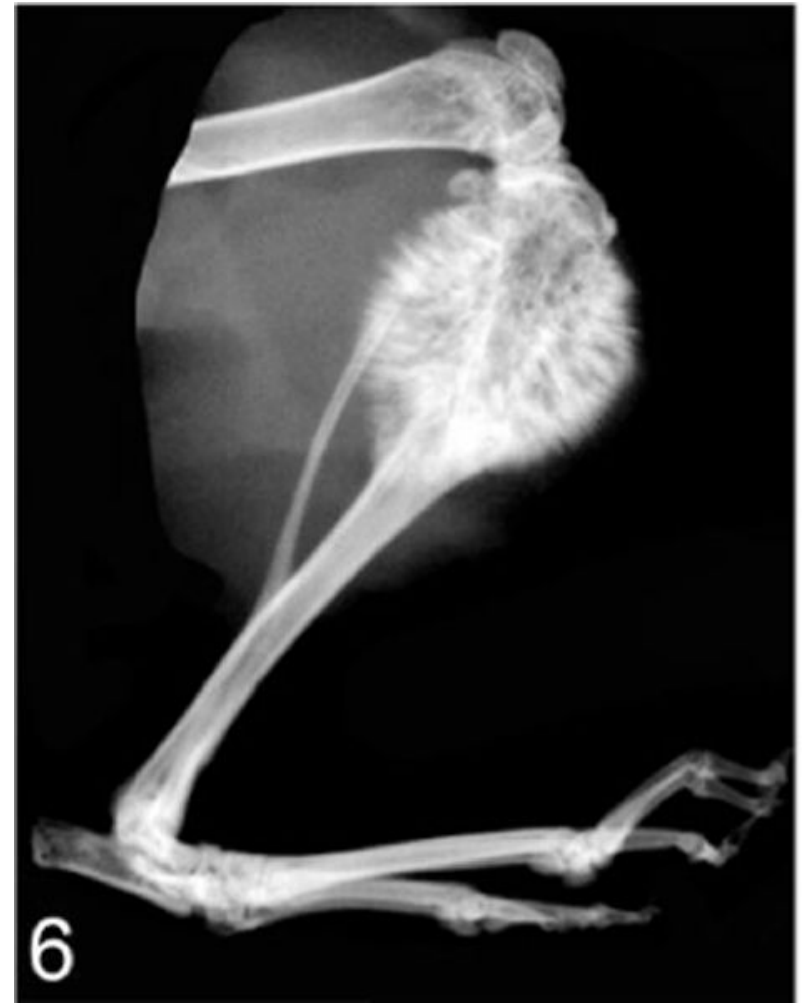

Figure 6.

Tibia, nude mouse. The parent Probasco canine prostate cancer cells induced an osteoblastic metastasis with marked intramedullary and periosteal bone formation 6 weeks after an intratibial injection of the cells. Faxitron radiograph. 


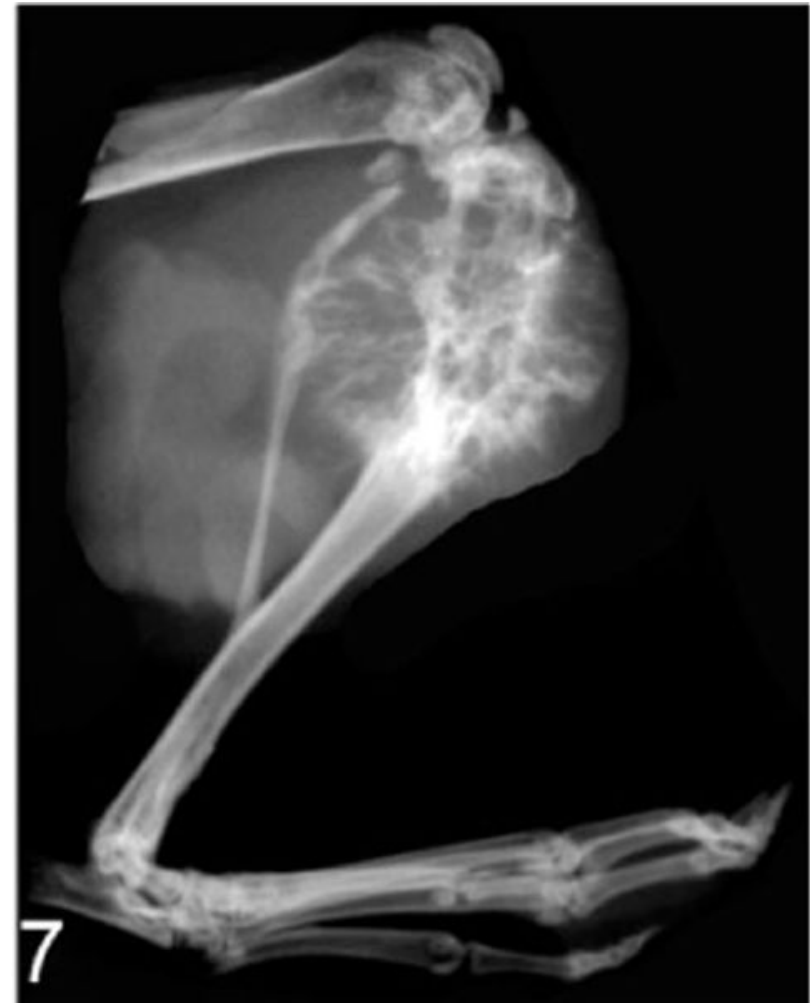

Figure 7.

The Probasco-PTHrP cells (stably transfected with human PTHrP) induced a mixed osteolytic and osteoblastic metastasis in the proximal tibia with increased bone resorption due to the actions of PTHrP. Faxitron radiograph. 


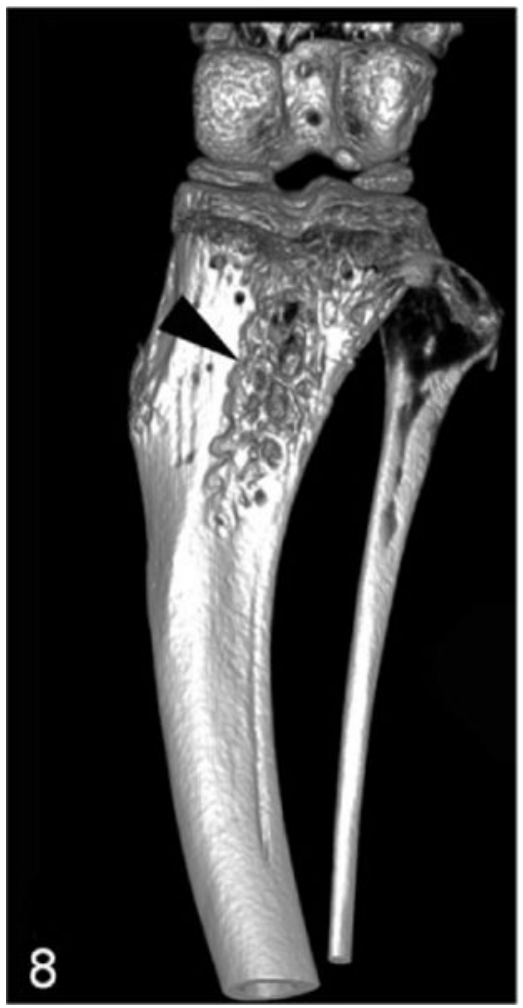

Figure 8.

Proximal tibia of a nude mouse, 3 weeks after intramedullary injection of Probasco canine prostate cancer cells with small areas of cortical bone loss (black arrowhead). Microcomputed tomography imaging with 3-dimensional reconstruction. 


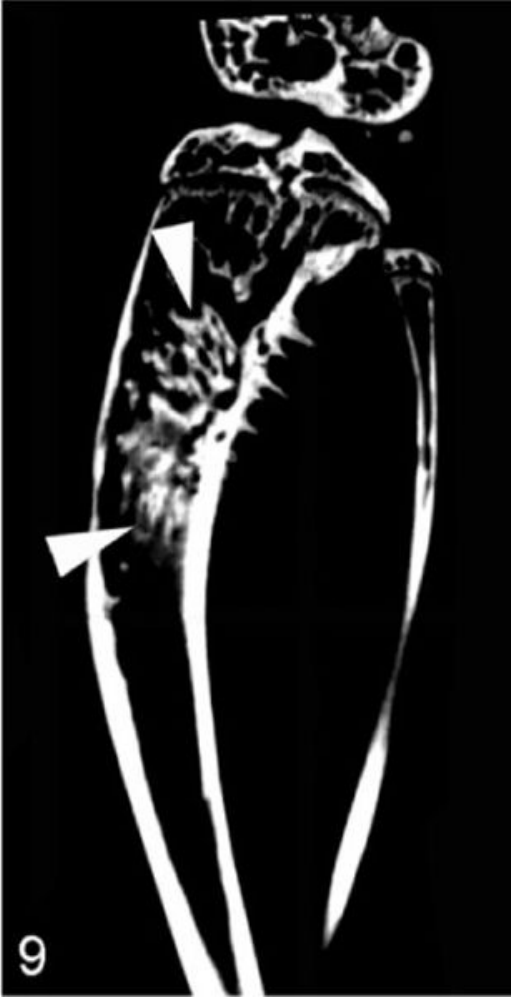

Figure 9.

Longitudinal section of the proximal tibia demonstrating new intramedullary trabecular bone formation (white arrowheads) in the metaphysis and diaphysis induced by the Probasco prostate cancer cells in an "osteoblastic" metastasis. Micro-computed tomography imaging. 

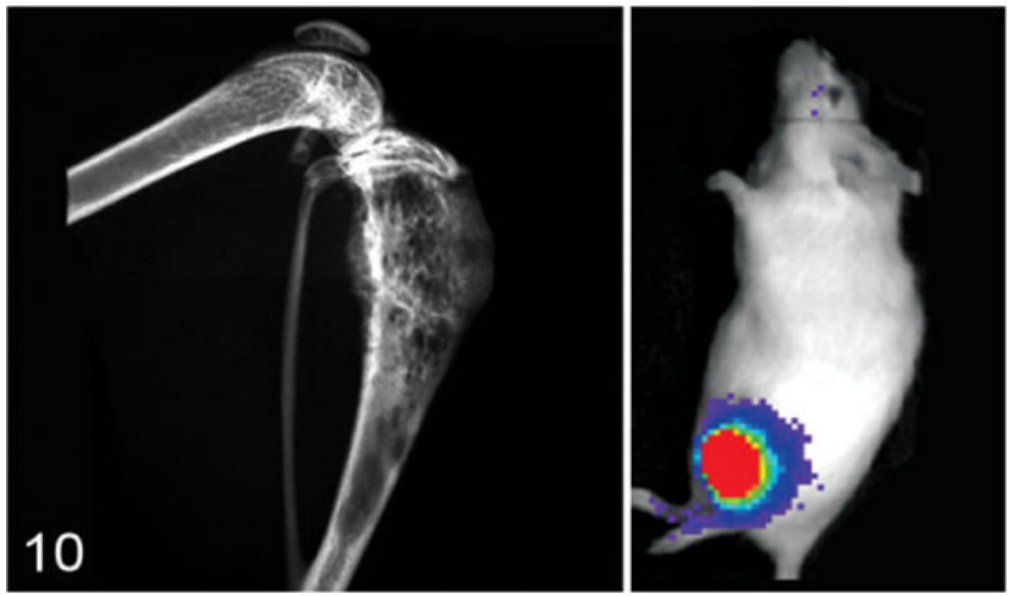

Figure 10.

Hind limb of a nude mouse with a Met-1 tumor (murine mammary cancer cell line) in the proximal tibia. Note bone lysis of the cortex and new bone formation in the medullary cavity in the radiograph (left). The inset (right) is a bioluminescent image of the Met-1 tumor in the tibia. Colors represent relative numbers of viable tumor cells: red $>$ yellow > green > blue. 


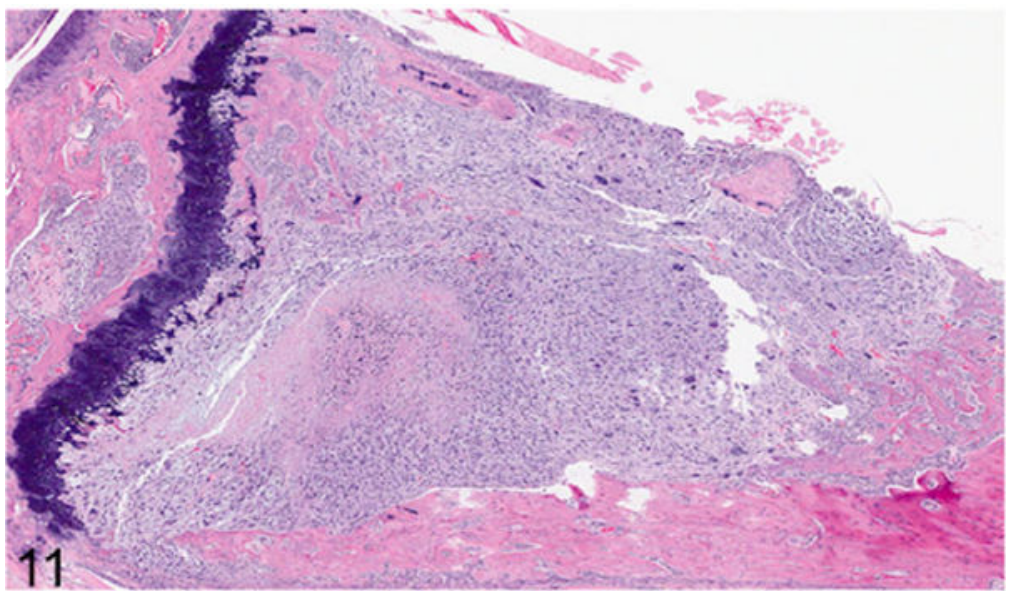

Figure 11.

Met-1 tumor in the proximal tibia. Note bone lysis of the cortex and new bone formation in the medullary cavity of the diaphysis. Hematoxylin and eosin (HE). 


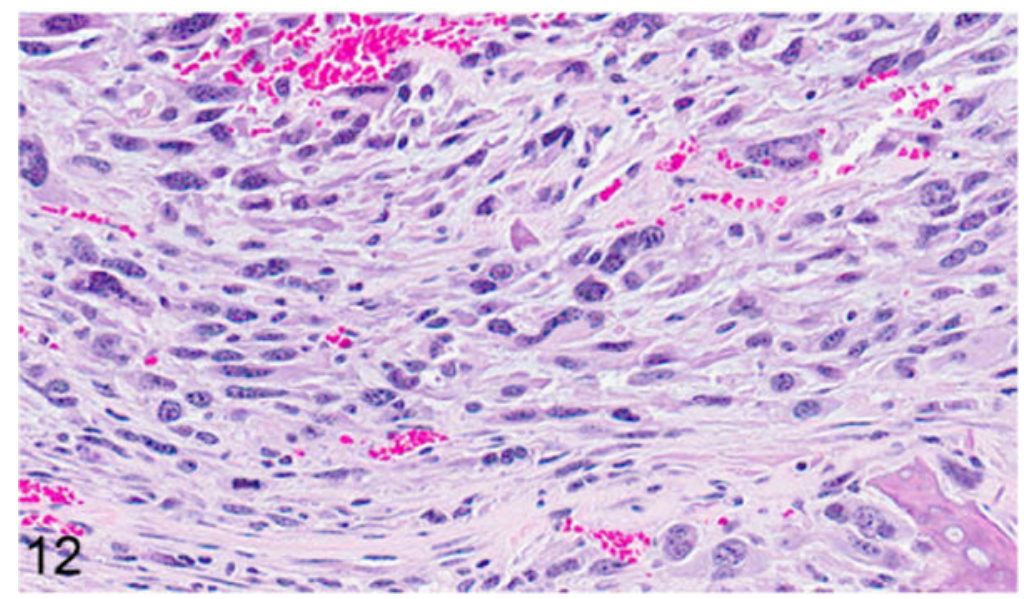

Figure 12.

Met-1 tumor in the proximal tibia. Met-1 bone tumors were mostly composed of spindleshaped cells and had minimal necrosis. HE. Reprinted from Werbeck et al. ${ }^{164}$ 


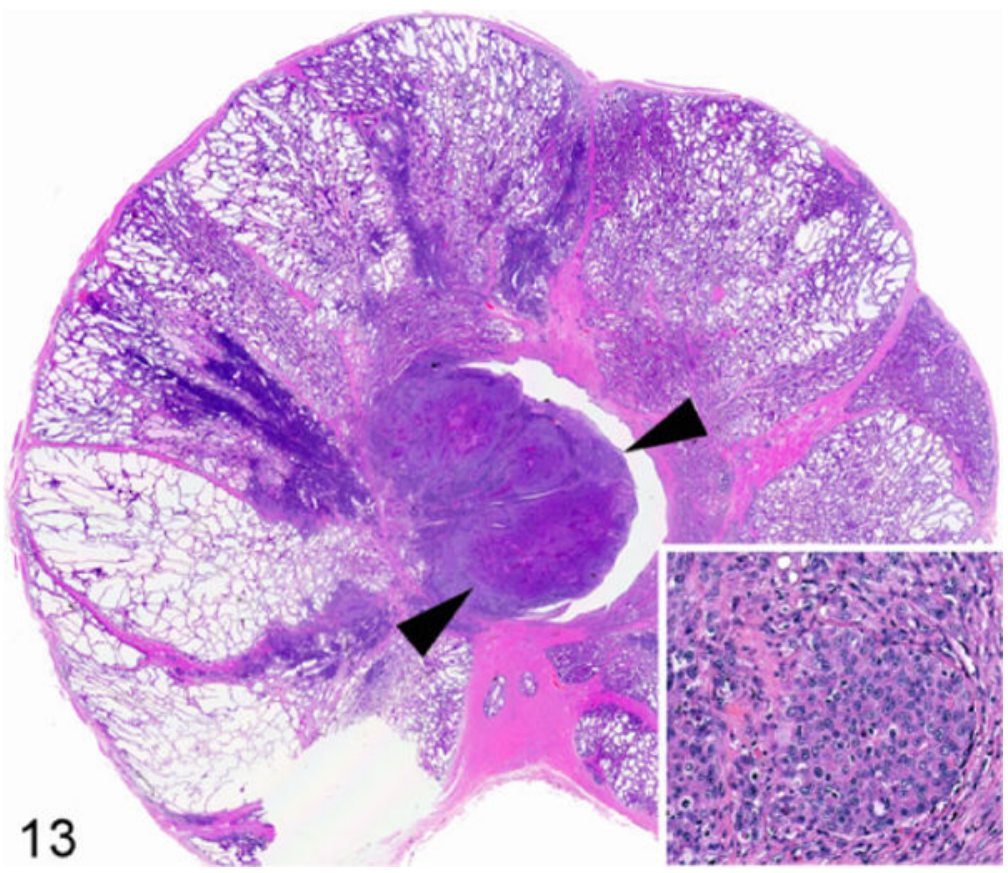

Figure 13.

Prostate gland, dog. Orthotopic prostate carcinoma (arrowheads) developed after intraprostatic injection of canine Ace-1 cells in a cyclosporine-A-treated adult male Beagle dog. Inset: Ace-1 prostate cancer cells. Hematoxylin and eosin. 


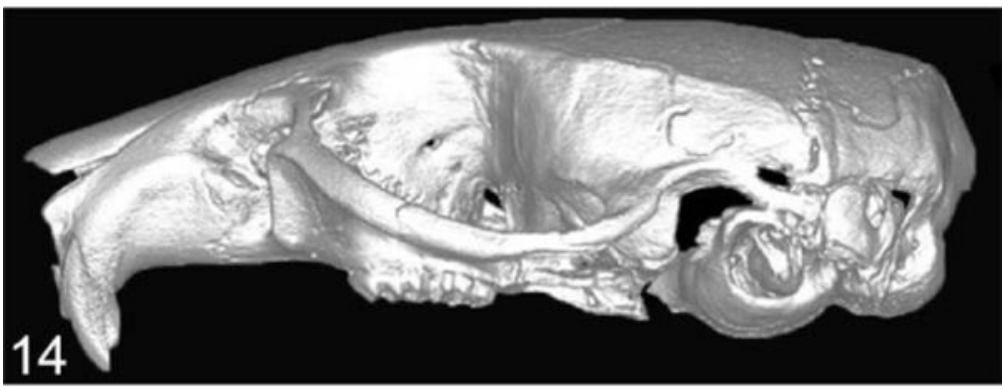

Figure 14.

Normal head of a nude mouse. Micro-computed tomography (CT) imaging. 


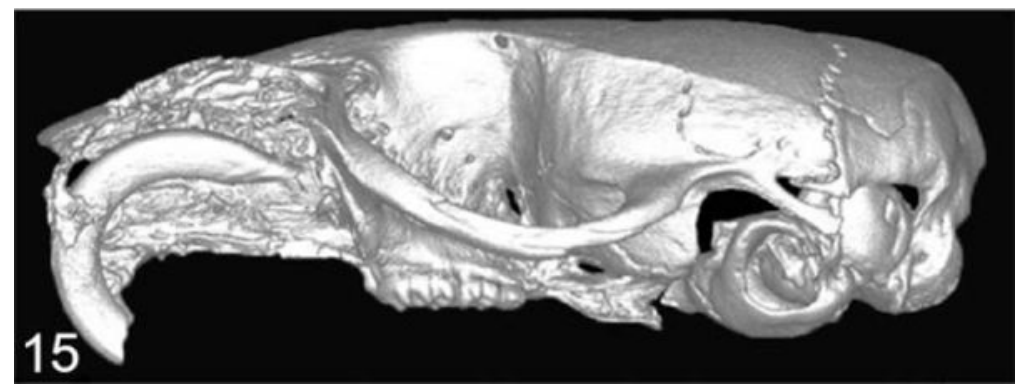

Figure 15.

Feline squamous cell carcinoma (SCCF2) was implanted into the maxillary gingiva, and severe bone lysis was induced by invasive carcinoma cells. Micro-CT imaging. 